\title{
WHOI-83-42
}

\section{FINDIF: A Software Package \\ to Create \\ Synthetic Seismograms by Finite Differences}

\author{
by \\ Mary M. Hunt, Lee Gove, \\ and \\ Ralph A. Stephen \\ Woods Hole Oceanographic Institution \\ Woods Hole, Massachusetts 02543
}

November 1983

\section{Technical Report}

Funding was provided by the Office of Naval Research under Contract N00014-79-C-0071; NR 083-004.

Reproduction in whole or in part is permitted for any purpose

of the United States Government. This report should be cited as:

Woods Hole Oceanog. Inst. Tech. Rept. WHOI-83-42.

Approved for public release; distribution unlimited.

Approved for Distribution:

Richard P. von Herzen, Chairman

Department of Geology and Geophysics 


\section{Abstract}

In order to study seismic wave propagation through laterally varying sea floor structures, a software package has been created to generate synthetic seismograms by finite differences. The elastic wave equation can be solved in two dimensions either for point sources in cylindrical coordinates or for line sources in rectangular coordinates. Vertical and radial variations of the elastic parameters are allowed.

The package includes four programs. Input to the system consists of a short file containing parameter values to describe the model. The first program is used to initialize the system for the particular model being used. The source arrays and velocity matrices are each computed by a separate program. The final program, which actually carries out the finite difference calculations, includes six subroutines to implement different options based on alternative finite difference formulations. Two different kinds of output files are created by this program: one or more snap-shot files, and one time series file, which will usually include more than one series. 


\section{CONTENTS}

$\underline{\text { Page }}$

Abstract $\quad i$

I. Introduction 1

II. The Model 2

III. The Programs 5

IV. The files 8

V. The Subprograms 12

$\begin{array}{ll}\text { VI. Implementation Notes } & 14\end{array}$

$\begin{array}{ll}\text { VII. Usage on the VAX } & 15\end{array}$

$\begin{array}{ll}\text { VIII. Error Messages } & 18\end{array}$

IX. Sample Runs $\quad 20$

X. Notes on Parameter Specifications 36

$\begin{array}{lll}X I \text {. References } & 37\end{array}$

Appendix: Performance Evaluation 38 


\section{Introduction}

This report describes a software package used to generate synthetic seismograms by calculating the elastic wave equation in two dimensions by finite differences. The original finite difference code, which includes Kelly, Alterman, Il an and Stephen formulations for cylindrical and rectangular co-ordinates with two different source configurations, was developed and written by R. A. S. between 1978 and 1983. The absorbing boundary subroutine was written by Mr. S. Emerman and is reported in Emerman and Stephen, 1983. Applications of the code and comparison of the results with the reflectivity method are discussed in Stephen (1983). L. G. assisted throughout the development by providing programming advice, writing input/output code and file handling procedures. L. G. also ran or directed a series of 'bench mark' tests for performance evaluation on the VAX, on the VAX with an array processor, and on the Cyber 205. The results of these tests are reported in the Appendix. M. M. H, commencing in the spring of 1983, has further modified the code to be more 'user friendly' and to be more easily transportable. M. M. H. also prepared this manual which is being written in order to facilitate the use of the software package by new users.

The program development is an on-going process; further enhancements are continually being made. The version documented and released here is a temporary stopping-place.

The program uses a variety of explicit finite difference techniques to solve the following equation:

$$
\rho \vec{u}=(\lambda+\mu) \nabla(\nabla \cdot \vec{u})+{ }_{\mu} \nabla 2 \vec{u}+\nabla \lambda(\nabla \cdot \vec{u})+\nabla_{\mu} \times(\nabla \times \vec{u})+2(\nabla \mu \cdot \nabla) \vec{u}
$$

where

$$
\begin{aligned}
& \vec{u} \text { is the particle displacement vector } \\
& \lambda, \mu \text { are Lamé's parameters, and } \\
& \rho \text { is density. }
\end{aligned}
$$

The equation is solved in two dimensions either for point sources in cylindrical co-ordinates or for line sources in rectangular co-ordinates. Vertical and radial variations of the elastic parameters are allowed. The methods have been compared for accuracy with the reflectivity method by Stephen (1983). 


\section{The Mode 1}

The software depends heavily on the definition of the model, which is specified for the computer in the form of a model parameter file. A diagram of the model is given in Figure 1.

The model consists of three horizontal layers; the top layer is water, the middle layer is the sea-floor boundary layer, and the bottom layer is the sub-surface stratum. The top and bottom layers are assumed to be homogeneous, with a constant velocity. The boundary layer has a varying structure; the velocities within this layer are calculated by Program FDBNY. A grid is superimposed on the entire area of the model. The grid is divided into NN depth divisions, and MM distance (or range) divisions. The energy source is assumed to be located on the left edge of the model. The right edge and the bottom edge of the model are either rigid or absorbing boundaries.

There are two categories of parameters in the model parameter input file. Some parameters describe the physical model, and others describe the desired processing and output. A description of all parameters, in alphabetical order, is given in Table I. All times are in seconds, and distances are in kilometers. 
Figure 1

DIAGRAM OF MODEL

FANGE-IIEFTH CFOSS SECTION: ISOFE $=0$, IFLAT $=0$

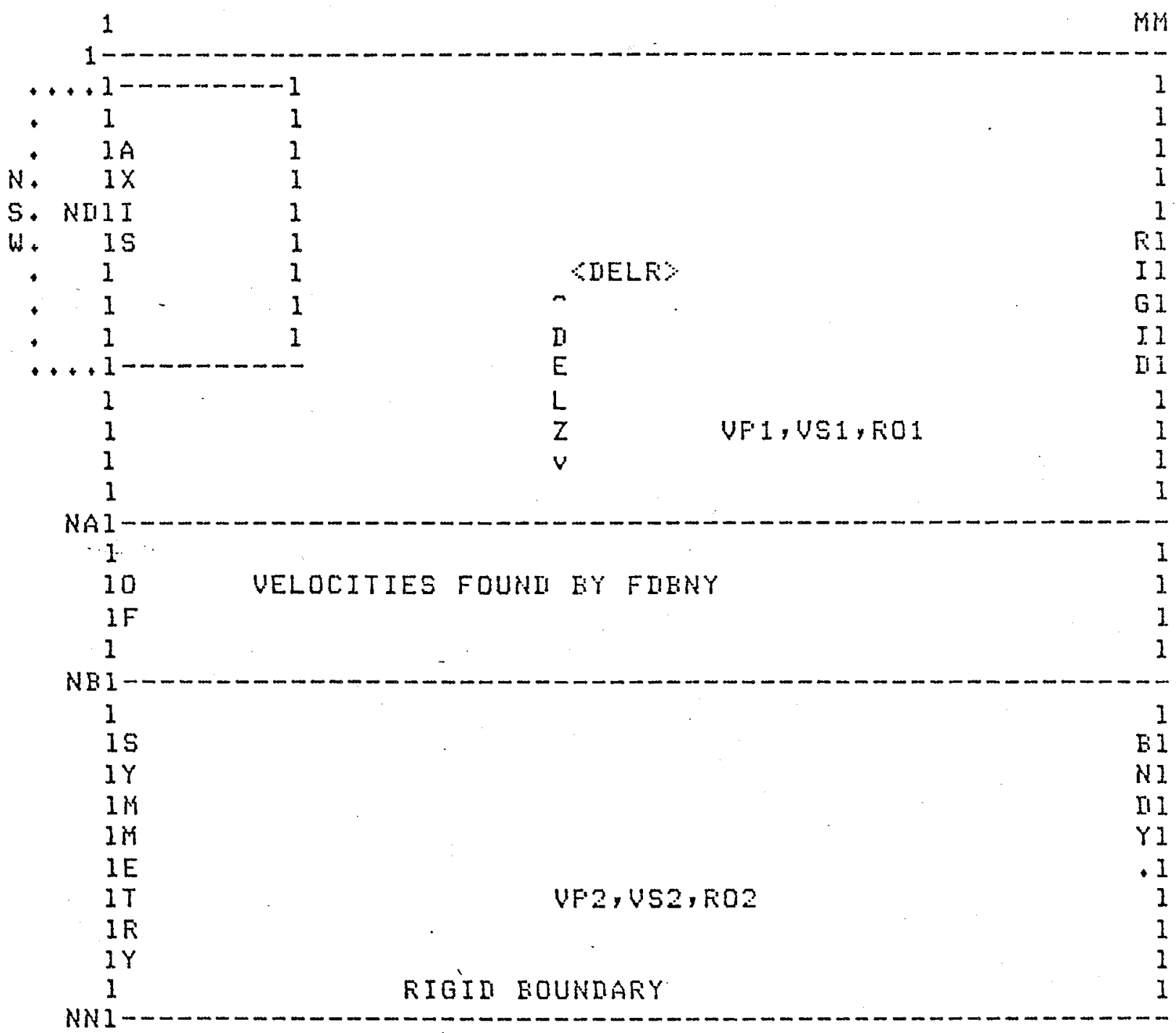




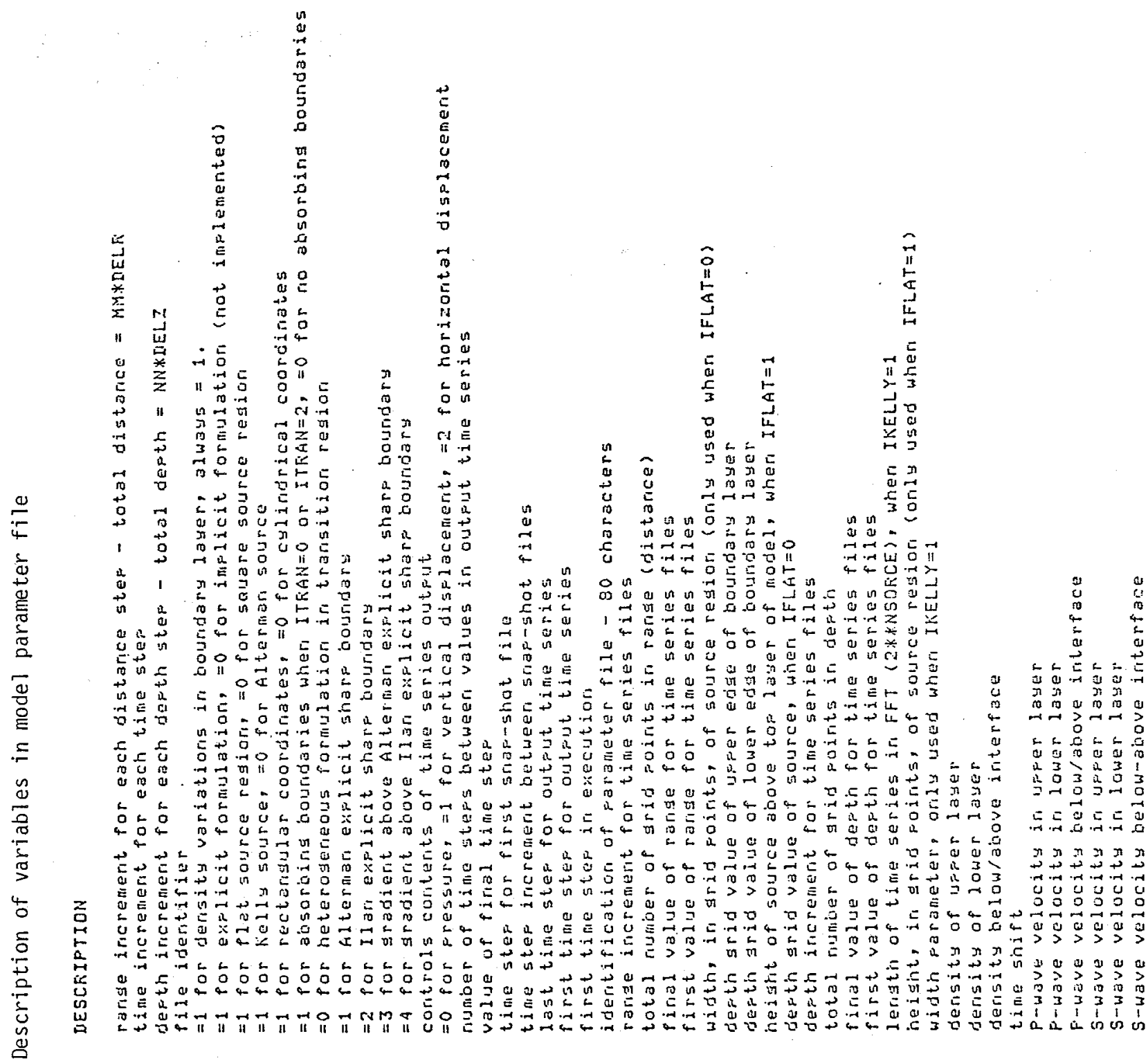

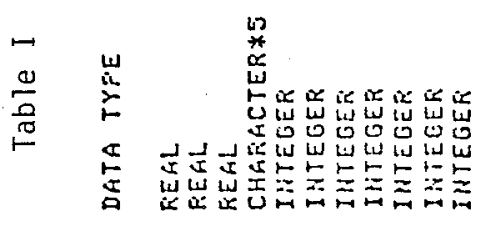

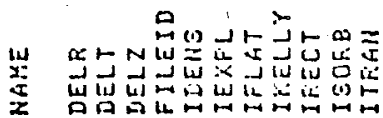

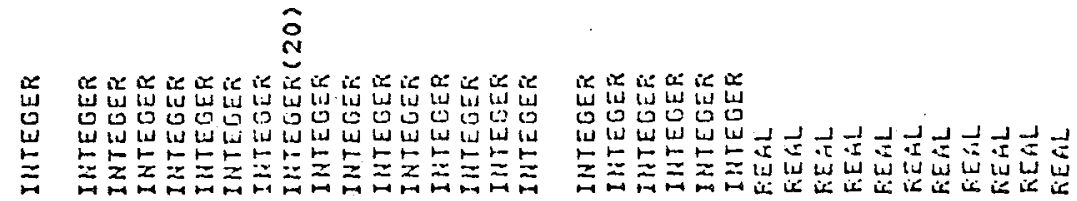

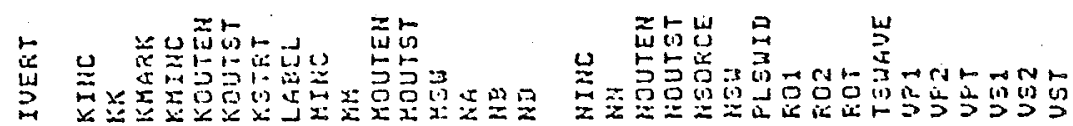




\section{The Programs}

The package includes four programs. Input to the system consists of a short file containing parameter values to describe the model, and to specify the amount of output desired. The final output includes two different kinds of files: one or more snap-shot files, and one time series file, which will usually include more than one series.

In an effort to minimize the computer resources used for a given model, minimum array sizes are computed and the specifications are stored in COMMON files. These files are then accessed during compilation by using INCLUDE statements in the programs. The charges incurred by running a model with larger than necessary arrays are usually greater than COMPILE and LINK charges.

The first program in the sequence, FDPREP, checks the model parameters for validity, and determines the correct dimensions for the arrays needed by the other programs. Two files are created with COMMON specifications correctly formatted for INCLUDE statements. Descriptions of the arrays in these COMMON blocks are given in Table II.

The second program, FDSORS, calculates sources. The program creates a file containing the model parameters which were used, and the source arrays computed.

The third program, a version of FDBNY, finds the matrices of P- and Svelocity squared, and the density matrix of the boundary layer for the model. This program also creates a file, containing model parameters used and the three matrices which were calculated.

The final program, FINDIF, uses the model parameter file, and the files produced by the other two programs, to create the final output. The snap-shot files give values of vertical displacement over the entire grid at the specified times. The time series give values of vertical displacement, horizontal displacement, or pressure at each of the selected grid points for the specified time interval.

Program FDSORS must be compiled using the specifications for COMMON block COMSOR which were found by FDPREP. Programs FDBNY and FINDIF must be compiled using the specifications for COMMON block COMFD8. All programs create a log file to give a permanent record of what was done. A diagram of the system is given in Figure 2 . 
Table II

Contents of COMMON block /COMFD8/

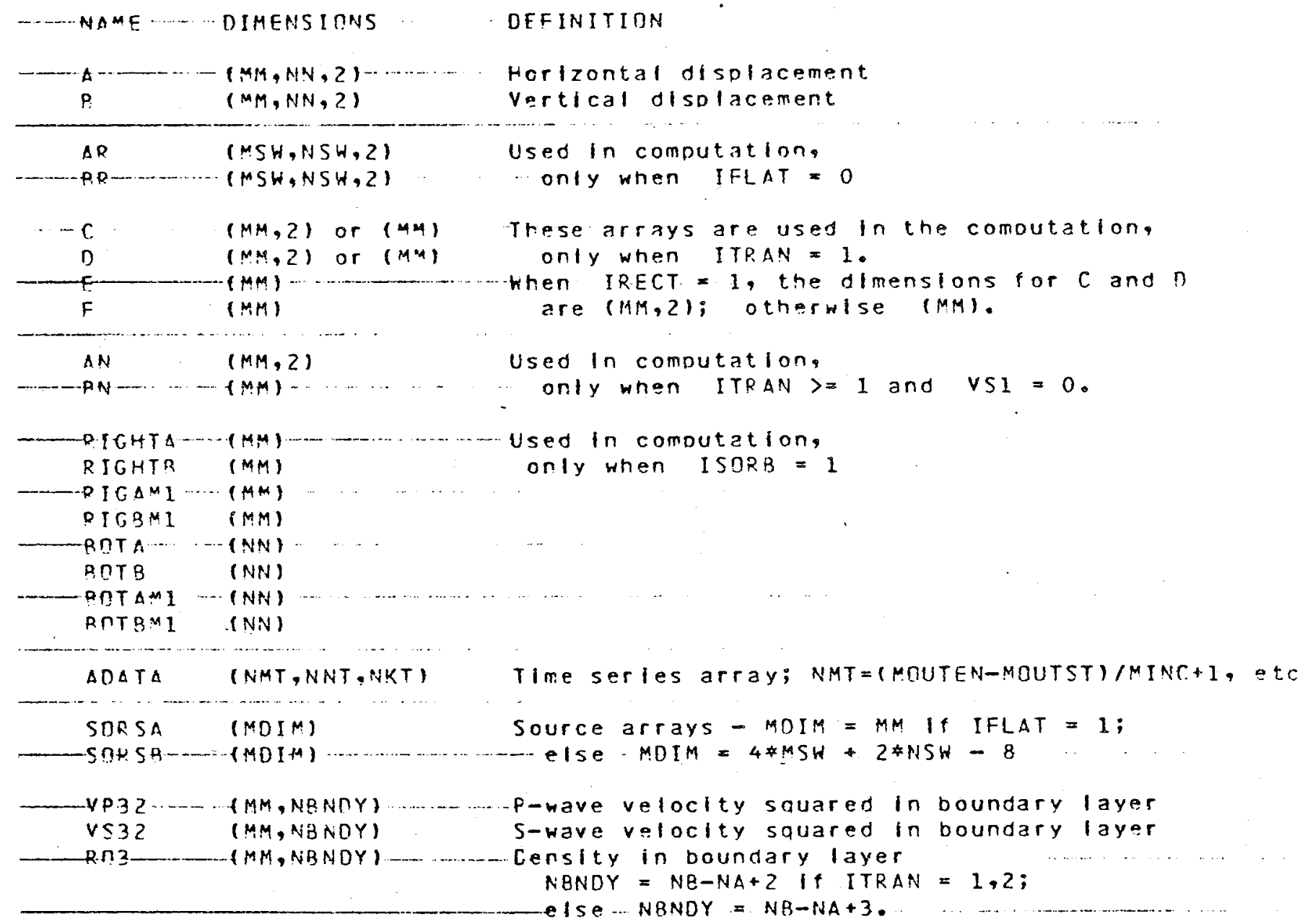

Contents of CONifoN block /COMSOR/

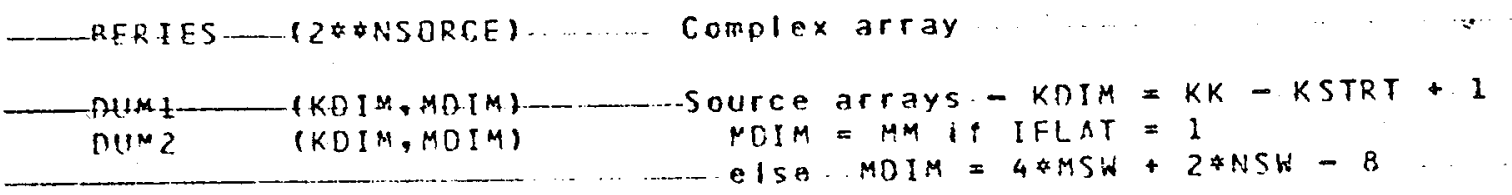


Figure 2

SYSTEM DIAGRAM

Input

Programs

Intermediate files

Output

files

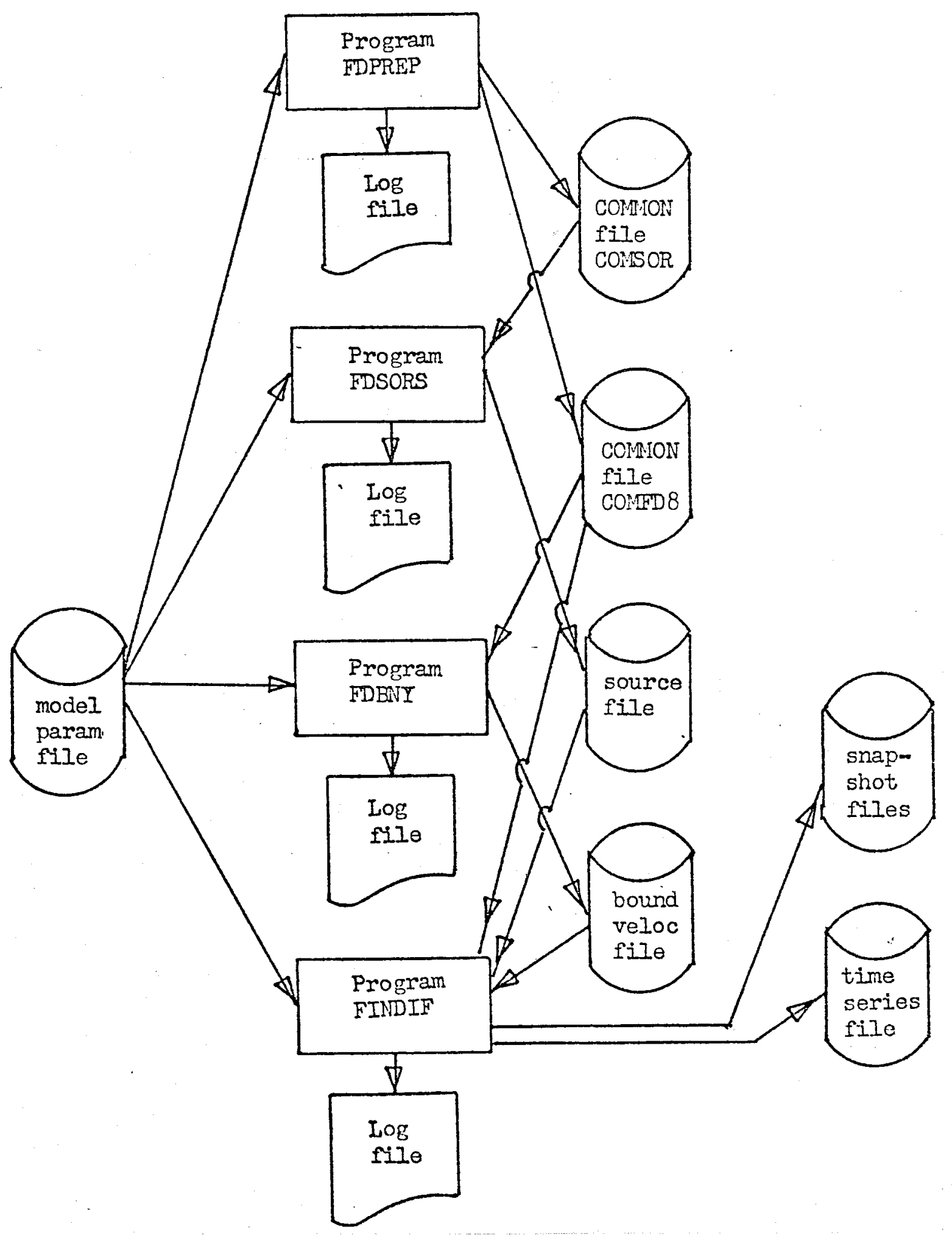


IV. The Files

A. Model Parameter File

This is a sequential formatted file, most of which is read with

list-directed READ statements (free-field input). The Fortran unit number is 55. The record contents follow.

1. Record 1 consists of up to 80 characters containing identification for the model.

2. Record 2 contains, in the first 5 characters, identification used in the names of input and output files.

3. Record 3 (free-field) contains values of:

IRECT, IDENS, IFLAT, IKELLY, IEXPL, IVERT, ITRAN, ISORB

4. Record 4 (free-field) contains values of:

MM, NN, KK, KSTRT, DELT, DELR, DELZ

5. Record 5 (free-field) contains values of:

KOUTST, KOUTEN, MOUTST, MOUTEN, NOUTST, NOUTEN

6. Record 6 (free-field) contains values of:

KINC, MINC, NINC, KMARK, KMINC

7. Record 7 (free-field) contains values of:

VP1, VS1, R01, VP2, VS2, R02, NA, NB, VPT, VST, ROT

8. Record 8 (free-field) contains values of:

ND, MSW, NSW

9. Record 9 (free-field) contains values of:

NSORCE, PLSWID, TSWAVE

B. Boundary velocity file

This file is created by FDBNY, and is read by FINDIF. It is a sequential, unformatted file, created with binary WRITE

statements. The Fortran unit number is 54. The records are:

1. Record 1 contains values of:

IEXPL, IDENS, MM, NA, NB 
2. Record 2 contains values of: VP1, VS1, R01, VP2, VS2, R02

3. Record 3 contains all values of array VP32. The first dimension of this array is the value of MM. The second dimension is the value of

$$
\begin{aligned}
\text { NBNDY } & =N B-N A+2 & & \text { when } \quad \text { ITRAN }=1 \text { or ITRAN }=2 \\
& =N B-N A+3 & & \text { otherwise }
\end{aligned}
$$

4. Record 4 contains all values of array VS32. Dimensions are the same as VP32.

5. Record 5 is used only when IDENS $=1$. It contains all values of array R03. The dimensions are the same as VP32.

\section{Source File}

This file is created by FDSORS, and is read by FINDIF. It is a sequential, unformatted file,-created with binary WRITE statements. The Fortran unit number is 50 . The records are:

1. Record 1 contains values of:

IEXPL, IFLAT, IKELLY, VP1, KSTRT, KK, IRECT

2. Record 2 contains values of:

ND, MSW, NSW, DELT, DELZ, DELR, NSORCE, PLSWID, TSWAVE

3. Record 3 contains values of SORSA for the first time step. The dimension of SORSA is:

$$
\begin{array}{llll}
M M & \text { if } & \text { IFLAT }=1 \\
4 * M S W+2 * N S W-8 & \text { if } & \text { IFLAT }=0
\end{array}
$$

4. Record 4 contains values of SORSB for the first time step. The dimension is the same as for SORSA.

Records 3 and 4 are repeated for each time step. Total number of these two records is KK - KSTRT +1 .

D. Snap-shot Files

Snap-shot files are created by FINDIF. They are sequential, unformatted files, created with binary WRITE statements. The Fortran unit number is 3 . The first snap-shot file is created at 
time step KMARK. Thereafter, a snap-shot file is created every KMINC timesteps, until the final timestep (KK) is reached. The names of these files are created by the program. The first 5 characters are the FILEID. The next 4 characters are the numeric value of the timestep. The file extent is.SNS. The contents of these files follow:

1. The first record contains values of all integer variables in COMMON block MODPAR. These variables are:

LABEL (20), IRECT, IDENS, IFLAT, IKELLY, IEXPL, IVERT, ITRAN, ISORB, NA, NB, ND, NSW, MSW, MM, NN, KK, KKSORS, KOUTST, KOUTEN, KINC, NOUTST, NOUTEN, NINC, MOUTST, MOUTEN, MINC, KSTRT, KMARK, KMINC, NSORCE, KCNT, NSAMP

2. The second record contains values of all real variables in COMMON block MODPAR. These variables are:

VP1, VP2, VPT, VS1, VS2, VST, R01, R02, ROT, DELT, DELR, DELZ, PLSWID, TSWAVE, TIME

3. The third and last record contains values of vertical displacement over the entire grid (MM * NN values).

E. Time Series File

This file is created by Program FINDIF. It is a sequential, unformatted file, created with binary WRITE statements. The Fortran unit number is 2. The name of the file is the same as FILEID, with an extent of .TST. The contents of the time series file are controlled by the value of IVERT. If IVERT $=0$, the $f i$ le will contain values of pressure; if IVERT $=1$, it will contain values of vertical displacement; if IVERT $=2$, it will contain values of horizontal displacement.

The number of individual time series is controlled by values of MOUTST, MOUTEN, MINC, and NOUTST, NOUTEN, and NINC. One series will be generated for every MINC' th range grid between MOUTST and MOUTEN, and every NINC'th depth grid between NOUTST and NOUTEN. Each time series will include every KINC'th time step between KOUTST and KOUTEN.

The contents of the records in the file are:

1. The first record contains values of all integer variables in COMMON block MODPAR. These variables are listed in the snap-shot file description.

2. The second record contains values of all real variables in COMMON block MODPAR, listed in the snap-shot file description. 
3. The third record contains the following:

LABEL (I), I =1,5
MOC
NLOC
KCNT
NSAMP
RANGE
TIME
ADMAX

$\operatorname{LABEL}(\mathrm{I}), I=1,5$

KCNT

NSAMP

TIME

ADMAX

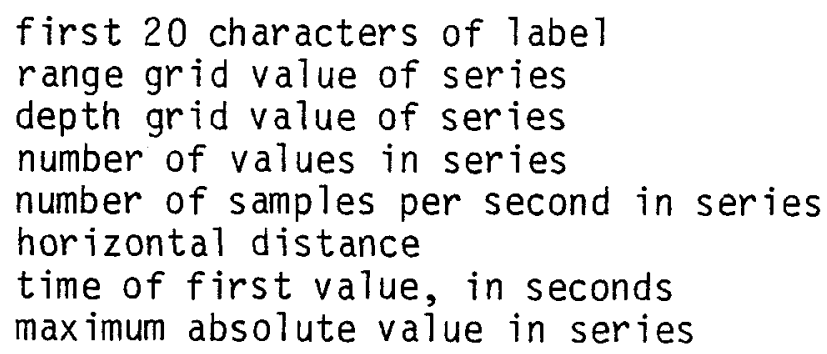

4. This record contains the time series described in record 3 . Record types 3 and 4 are repeated for as many time series as requested. 
V. The subprograms

A number of subprograms are included. These are listed, with brief descriptions, in Table III. It will be noted that there are 6 different TSTEP routines. The one used depends on the values of IRECT, VSI, and ITRAN, according to the table below.

$\begin{array}{clcc}\text { IRECT } & \text { VS1 } & \text { ITRAN } & \text { TSTEP } \\ 1 & \neq 0.0 & 0 & 1 \\ 1 & \neq 0.0 & 1 & 1 \\ 1 & \neq 0.0 & 2 & 1 \\ 1 & =0.0 & 0 & 1 \\ 1 & =0.0 & 2 & 3 \\ 0 & \neq 0.0 & 0 & 2 \\ 0 & \neq 0.0 & 1 & 2 \\ 0 & \neq 0.0 & 3 & 5 \\ 0 & \neq 0.0 & 4 & 6 \\ 0 & =0.0 & 0 & 2 \\ 0 & =0.0 & 1 & 4 \\ 0 & =0.0 & 2 & 4 \\ 0 & =0.0 & 3 & 5 \\ 0 & =0.0 & 4 & 6\end{array}$

Combinations other than these have not been implemented. 
Table III

Subprograms used.

\begin{tabular}{|c|c|c|c|}
\hline NAME & Used by & $\begin{array}{l}\text { Variable } \\
\text { COMMON } \\
\text { needed }\end{array}$ & Function \\
\hline LOGOUT & al1 & none & Creates first part of $\log$ file \\
\hline RDMPAR & a)1 & none & Reads model parameter file \\
\hline DATIM & a)1 & none & $\begin{array}{l}\text { Access current date and time from } \\
\text { operating system, and writes them. }\end{array}$ \\
\hline OPNCOM & FDPREP & none & Opens files for COMMON specifications \\
\hline BE SJ & FDSORS & none & Computes Bessel function values $\mathrm{JO}$ or $\mathrm{J} 1$ \\
\hline BESY & FDSORS & none & Computes Bessel function values $\quad Y_{0}$ or $Y_{1}$ \\
\hline $\mathrm{COOL}$ & FDSORS & none & Does FFT \\
\hline KELLY7 & FDSORS & COMSOR & Finds displacement due to Kelly source \\
\hline SOURCE & FDSORS & none & Finds displacement due to Alterman source \\
\hline$A B S O R B$ & FINDIF & COMF D8 & Does absorbtion calculation \\
\hline CONIT & FINDIF & COMFD8 & Initializes variables and arrays \\
\hline FSETUP & FINDIF & none & Opens files \\
\hline SNP OUT & FINDIF & none & Outputs snap-shot file. \\
\hline TSOUT & FINDIF & none & Outputs time series file. \\
\hline $\begin{array}{l}\text { TIMI T } \\
\text { TIMSHO }\end{array}$ & FINDIF & none & $\begin{array}{l}\text { Initializes system timer } \\
\text { Entry to TIMIT, finds elapsed time. }\end{array}$ \\
\hline $\begin{array}{l}\text { TSTEP } 1 \\
\text { TSTEP } 2 \\
\text { TSTEP } 3 \\
\text { TSTEP } 4 \\
\text { TSTEP } 5 \\
\text { TSTEP } 6\end{array}$ & FINDIF & COMF D8 & $\begin{array}{l}\text { These routines compute the displacements } \\
\text { for one time-step. }\end{array}$ \\
\hline
\end{tabular}


VI. Implementation Notes

The programs have been written in Fortran 77 for a VAX 11/780 under VMS. An effort has been made to avoid non-standard features. Specificaliy, all identifiers are 6 characters or less, and the DO WHILE feature is not used. The programs all use the BLOCK IF capability, and do use character variables. If the INCLUDE statement is not available, programs and some subroutines will have to be edited to change some of the array dimensions. The various TSTEP routines are rather long, so we have created a subroutine library which includes dummy versions of them. When we load FINDIF, we specifically include the TSTEP needed, and satisfy the unused references to the other TSTEP routines from the library. It may be necessary at some installations to use some other technique.

An effort has been made to isolate all input and output, and all non-standard features, in subroutines. The following routines might need changes:

TIMIT to initialize the system timer

TIMSHO, an ENTRY to TIMIT, finds elapsed CPU time

FSETUP opens output Log file, source file, and boundary velocity file

SNPOUT creates name of snap-shot file, opens file, writes data in file, and closes file

TSOUT creates name of time series file, opens file, writes data in file, and closes file

RDMPAR used by all programs, reads the model parameter file. It uses list-directed READ statements.

DATIM used by 211 programs, gets current date and time from operating system. OPNCOM used by FDPREP, opens files for new COMMON specifications. 
VII. Us age on the VAX

A. General

This section describes how the system is set up to run on the VAX here at WHOI. Changes might be needed for other computers. In general, ASSIGN commands are required for input files, and output file names are created by the programs using the FILEID from the model parameter file with a different file extent (or file type) for each output file.

B. Model Parameter File

The first step is to create a model parameter file. The contents of the records are listed in Section IV A, and descriptions of the variables are in Table I. All records except the first two are in free-field format, so spacing is not important. Let us, in this example, call this file MODEL.PAR, and let us use MODL1 as the file identifier.

C. RUN FDPREP

Next, Program FDPREP should be run. This program does the following:

1. Checks model parameters for consistency

2. Creates two COMMON block files:

COMFD8.FOR used by FDBNY and FINDIF

COMSOR.FOR used by FDSORS.

3. Creates a Log file summarizing its activities. In this case, the file will be MODL1.LGI

Before running FDPREP, you must use an ASSIGN command to connect the model parameter file to unit 55. Commands to run FDPREP are

SASSIGN MODEL.PAR FOR055

\$RUN FDPREP

D. Run FDBNY

Now Program FDBNY can be compiled and run. Here again, the only ASSIGN command required is for the model parameter file. The program reads this file and creates the following two files: 
1. The file defining the velocity structure in the transition zone. The name of this file will be MODL1.BNY

2. A $\log$ file, named MODL1.LG2

The commands to compile and run FDBNY are:

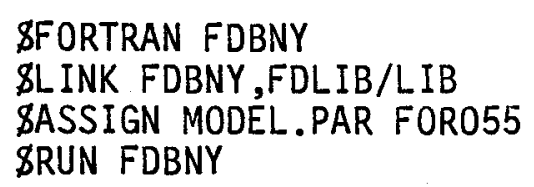

E. Run FDSORS

We can now compile and run Program FDSORS. This is similar to the procedure for FDBNY. The files created are:

1. A file defining the energy source for each time step. The name of this file will be MODL1.SOR

2. A $\log$ file, named MODL1.LG3

The commands to compile and run FDSORS are:

SFORTRAN FDSORS

\$LINK FDSORS,FDLIB/LIB

SASSIGN MODEL.PAR FOR055

\$RUN FDSORS

Subroutine KELLY7 is in the same file as FDSORS.

F. Run FINDIF

Finally, we can compile and run FINDIF. We must also compile the version of TSTEP which will be needed. This information is

included in the $\log$ file created by FDPREP. The commands to run FINDIF are:

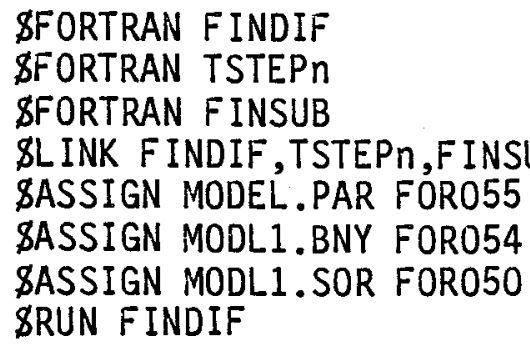


The files created by FINDIF are:

1. Log file, named MODLI.LG4

2. A time series file, named MODLI.TST

3. One or more snap-shot files. The names includes the time step. For example, a snap-shot file of time step 1000 will be MODL11000.SNS

G. Boundary and Source Files

It is not necessary to create new boundary and source files for each run of FINDIF. However, there are some parameters which must be the same as those used to create the files. For FDBNY, these parameters are MM, NA, NB, VP1, VS1, R01, VP2, VS2, and R02. For FDSORS, they are IFLAT, IKELLY, VP1, KSTRT, KK, ND, MSW, IRECT, DELT, DELZ, DELR, NSORCE, PLSWID, and TSWAVE. If any of these parameters in FINDIF is not the same as that used to create the boundary and/or source files, an error message is output, and FINDIF terminates. 
VIII. Error and Diagnostic Messages

The following error messages are included so the conditions causing the errors can be avoided.

A. FDPREP

1. The first two messages are the result of inconsistencies in the time step parameters. KSTRT and KK are the first and last time steps. KOUTST and KMARK are the first time step for time series and snap-shot files respectively. KOUTEN is the time step for the end of the time series. The messages are:

KOUTST $=$ or KMARK IS LESS THAN KSTRT $=$

KOUTEN $=$ IS GREATER THAN KK $=$

2. When IFLAT $=0$, NSW must be an odd number. If not, the following message will be output

NSW IS NOT AN ODD NUMBER - JOB STOPPED

3. Invalid combinations of parameters can produce the following: I NALID COMBINATION: ISORB $=$ IN ALID COMBI NATION: IRECT $=\_$VSI $=$ITRAN $=$

4. The last is a warning. The program will continue. WARNING - ABSORBING BOUNDARIES NOT CODED FOR THIS COMBI NATION.

\section{B. FINDIF}

1. The program will not run if the parameters used to create the boundary and/or source files do not match the current parameters. The messages are:

BOUNDARY PARAMETERS DO NOT MATCH

SOURCE PARAMETERS DO NOT MATCH

In each case, the offending parameter values are output.

2. The next message can appear only when the model parameter file is changed after running FDPREP, or the user does something stupid.

IN ALID COMBINATION OF PARAMETERS: . IRECT = ITRAN $=$ $V S 1=$ 
3. File errors:

ERROR

OPENING FILE

SNAP SHOT FILE ERROR. CODE $=$ KMARK $=$ ERROR ON TIME SERIES FILE. CODE $=$

As can be seen, in each case the error code is included in the message. 
IX. Sampie Runs

A group of sample runs was made, using the same basic parameters; the only changes in the parameter file were those required by the use of different options. The contents of the first model parameter file are listed with the output of the first run. The changes to create the other parameter files are given in Table IV. The sample run of the first model follows, step by step, the instructions in Section VII. Simple contour plots of the snap-shot files and some time series plots are included.

It will be noticed that the snap-shots for STEVB and STEVD (cylindrical coordinates and a square source) inciude some anonaijes in the source area. This noise is a result of the small size of the model and is not present in larger models.

\section{A. Model Parameter File}

Below is a listing of the model parameter file used in the first run. As can be seen, the name of the file is STEV1.PAR, and the FILEID is also STEV1. These two names do not have to be the same, a] though it saves some confusion if they are.

STEV1 FINAL TEST FOF FELEASE

STEU1

$1,1,1,1,1,1,0,1$

$72,72,300,1,0.008,0.04,0.04$

1. 300,1,72, 37, 37

$2,5,1,100,100$

$1.540,0,1,0,2,5,1,4,1.5,17,47,0,0,0.0,0.0$

$-11,0,0$

$10 ; 50.0 ; 0.5292$ 
Table IV

Parameter Values for Test Runs

Parameter

file Stev 1 Stev 2 Stev 3 Stev 4 Stev 5 steva stev b stev C stevd TSTEP routine

IFLAT

ND

MSW, NSW

11

2

3

$4 \quad 1$

2

3

4

1

1

1

10

0

0

$\begin{array}{lllllllll}-11 & -11 & -11 & -11 & -11 & 10 & 10 & 10 & 10\end{array}$

ITRAN

$$
0,0
$$

0,0

0,0

$0,0 \quad 5,11$

5,11

$5,11 \quad 5,11$

$\begin{array}{lll}0 & 0 & 0\end{array}$

2

2

0

0

2

2

$N A, N B$

$$
17,47 \quad 17,47
$$

$17,47 \quad 30,30$

30,30

17,47

17,47

30,30

30,30

IRECT

ISORB

1

1

1

0

1

0

1

0

1

0

10

\section{Boundary}

file

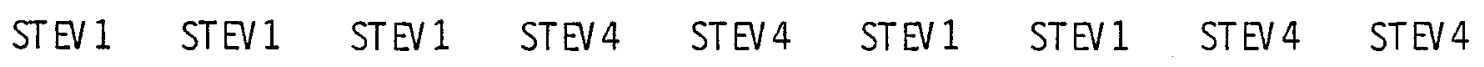
Source

file Stev 1 Stev 1 Stev 3 Stev1 Stev3 steva stevb steva stevb

FINDIF CPU time (Minutes) 
B. Run Program FDPREP

A listing of the log file is included

\$ ASSIGH STEVI. FAR FOROES

\$ RUN FIFREF

FIFREF COHFLETEII-NO ERRORS

\$ TYFE STEU1, LEI

FROGKAT FIFREF

FILE II IS. STEVI

VALUES OF INPUT PARAHETERS:
VERSION OF 20-EEF-Q3

DATE AID TIME OF RUN 23-SEF-83 13:50:48

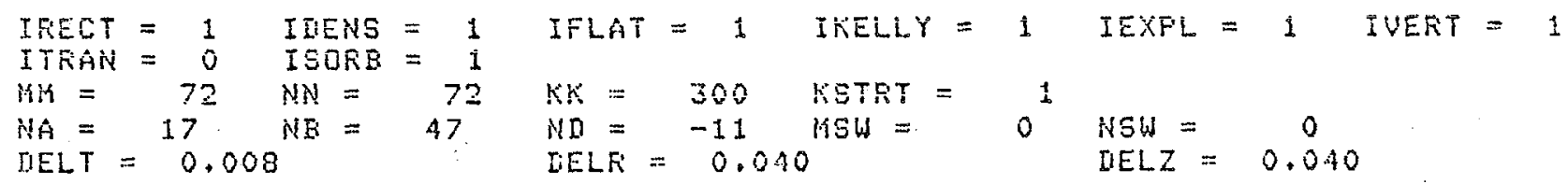

$\begin{array}{lrrr}\text { TIMES } & 1 & 300 & 2 \\ \text { FANGES } & 1 & 72 & 5 \\ \text { IIEFTHS } & 37 & 37 & 1 \\ \text { SNAPS } & 100 & & 100\end{array}$

VELOCTTIES:

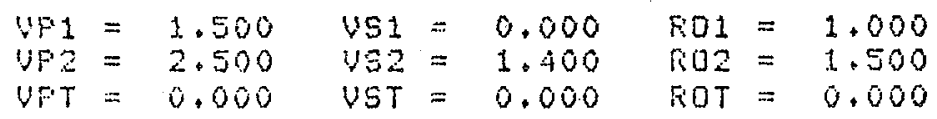

KELLY SOURCE PARAMETERS:

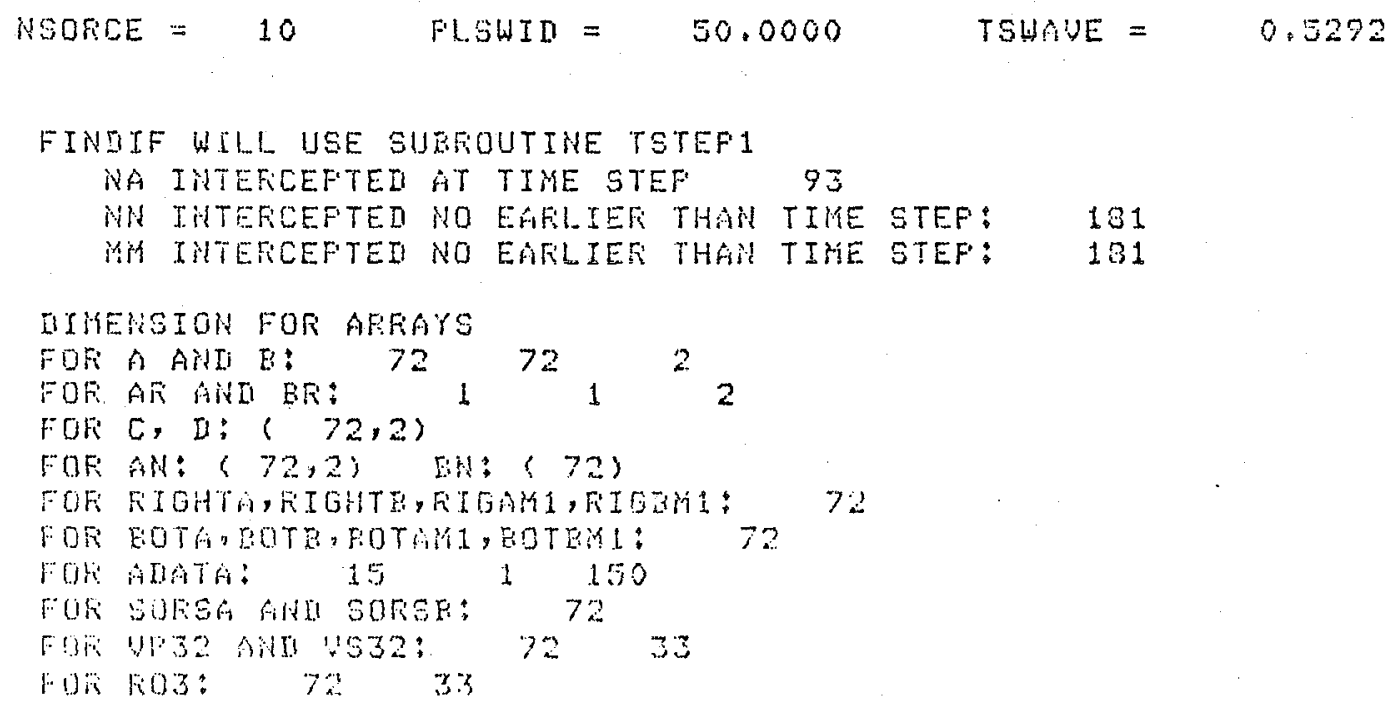


C. Compile, link and run FDBNY

Since this was done immediately after runnino FDPREP, we did not need to repeat the ASSIGN command for STEV1.PAR. A partial listing of the log file is included.

\$ FORTRAN FIENY

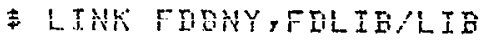

\$ FUN FIENY

FORTFAN STOP

D TYFE STEU1 + LG2

\section{FROGFAM FIENY}

FILE II IS STEU1

WALUES OF INFUT PARAMETERS:

\author{
VEFSION OF 9-JUL-33 \\ DATE AND TIME OF RUN $2.3-5 E P-83$ 13:51:51
}

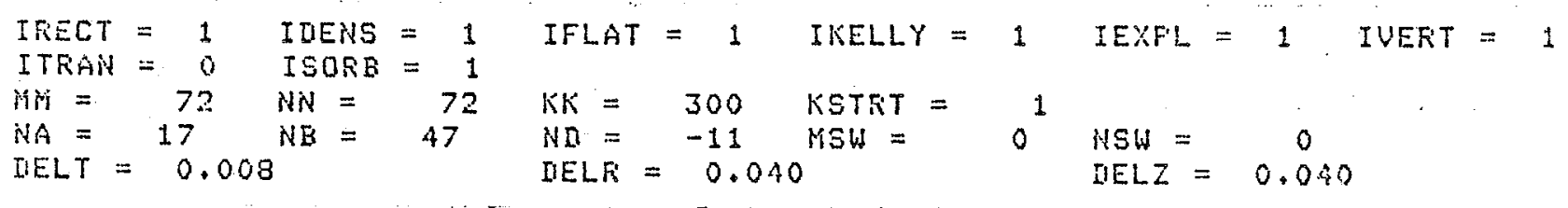

\section{VELOCITIES:}

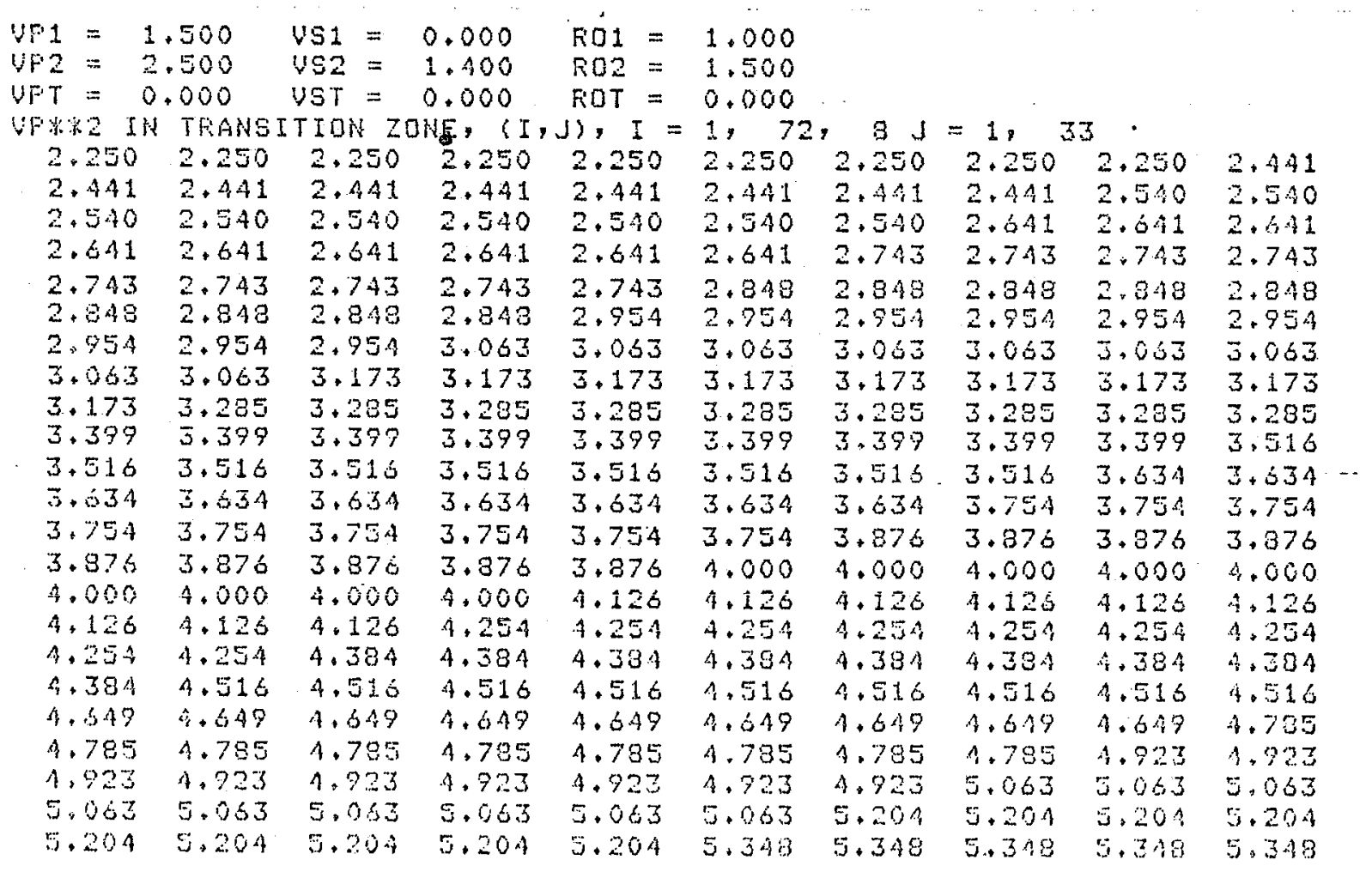


D. Compile, link, and run FDSORS

Again, we have included a listing of the log file.

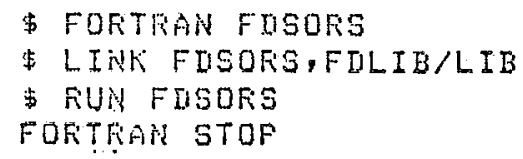

\$ TYFE STEU1.LG3

\section{FROGRAM FISORS}

FILE II IS STEVI

UALUES OF IAFUT FARAMETERS:
VERSION OF 12-SEF-G3

IATE ANID TIME UF KUUN $2 \overline{3}-5 E F-33$

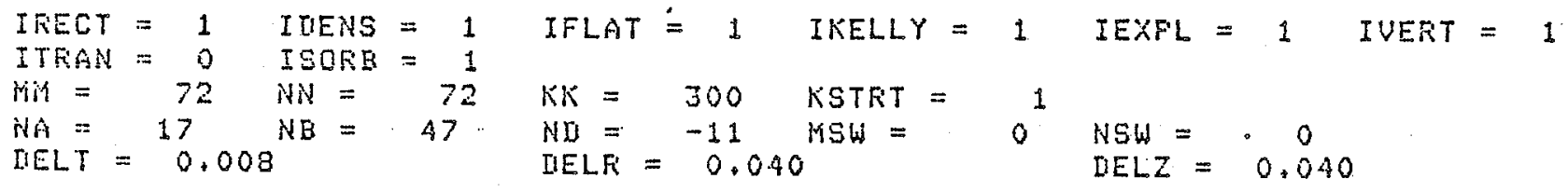

DUTFUT SFANS AND INCFEMENTS:

$\begin{array}{lrrr}\text { TTMES } & 1 & 300 & 2 \\ \text { RANGES } & 1 & 72 & 5 \\ \text { IEFTHS } & 37 & 37 & 1 \\ \text { SNAFS } & 100 & & 100\end{array}$

VELOCITIES:

$\begin{array}{lll}\text { UF1 }=1.500 & \text { US1 }=0.000 & \text { FOL }=1.000 \\ \text { UF2 }=2.500 & \text { US2 }=1.400 & \text { RO2 }=1.500 \\ \text { UFT }=0.000 & \text { UST }=0.000 & \text { ROT }=0.000\end{array}$

KELLY SOUACE FARAMETERS:

HSORCE $=10 \quad$ PLSWII $=\$ 0.0000$ TSWAVE $=0.5292$ 
E. Run FINDIF

Finally, we compile, link, and run FINDIF. We use TSTEP1 because Program FDPREP informed us which TSTEP routine would be needed. As can be seen, Program FINDIF displays the elapsed time and CPU time every 50 time steps. The log file is included on the next page.

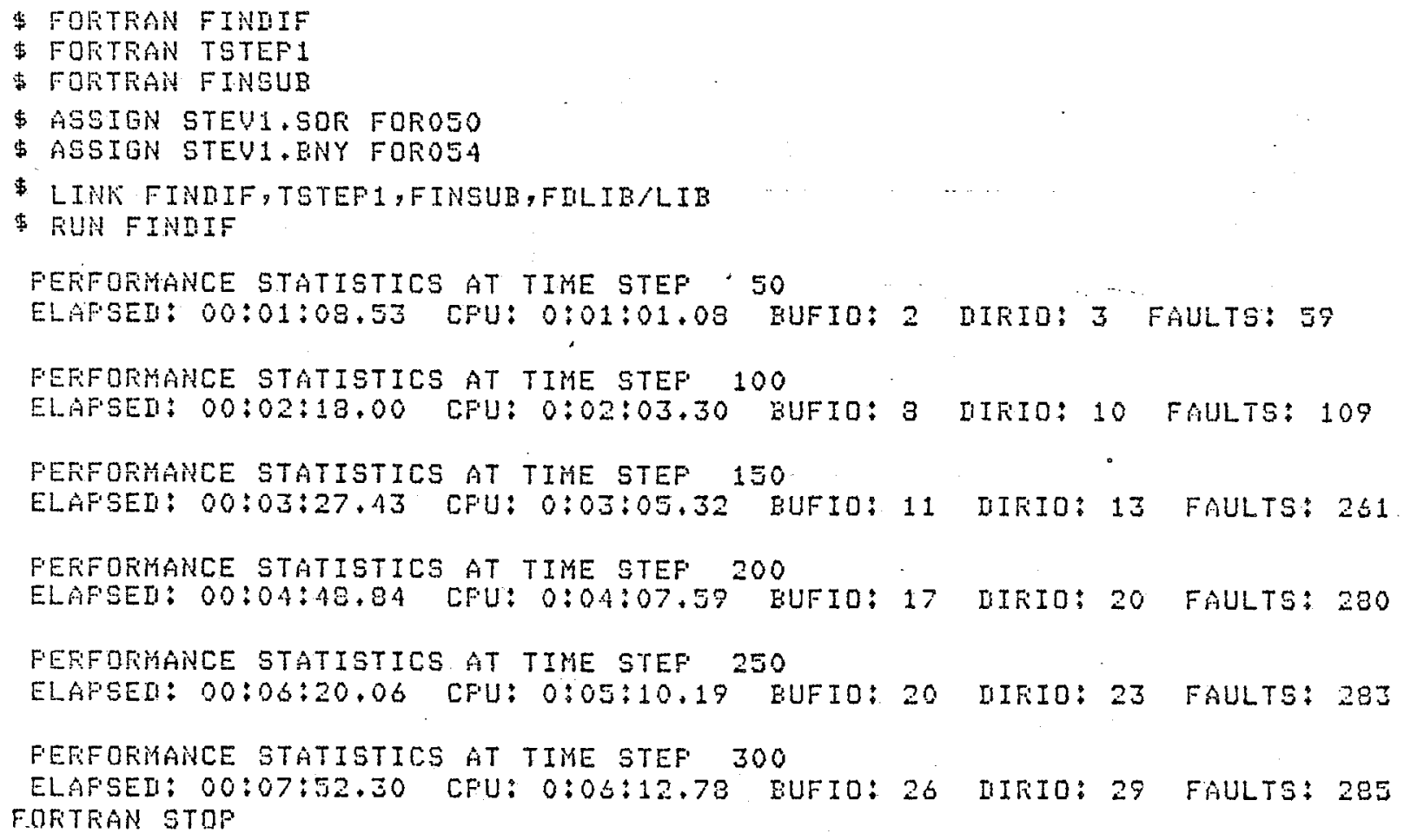


\$ TYPE STEUT.LG4

FROGRAM FINDIF

FILE ID IS STEVI

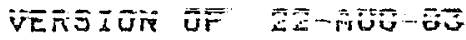

DATE ANI TIME OF RUN 23-SEF-83 13:59:56

VALUES OF INFUT PARAMETEKS:

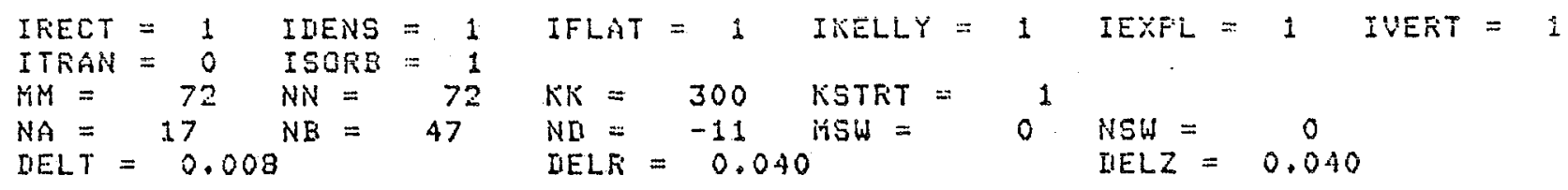

DUTPUT SFANS AND INCREMENTS:

$\begin{array}{lrrr}\text { TIMES } & 1 & 300 & 2 \\ \text { RANGES } & 1 & 72 & 5 \\ \text { IIEFTHS } & 37 & 37 & 1 \\ \text { SNAFS } & 100 & & 100\end{array}$

VELOCITIES:

$\begin{array}{lll}\text { VF1 }=1.500 & \text { US1 }=0.000 & \text { RO1 }=1.000 \\ \text { UF2 }=2.500 & \text { US2 }=1.400 & \text { RO2 }=1.500 \\ \text { UFT }=0.000 & \text { UST }=0.000 & \text { FOT }=0.000\end{array}$

KELLY SOURCE FARAHETERS:

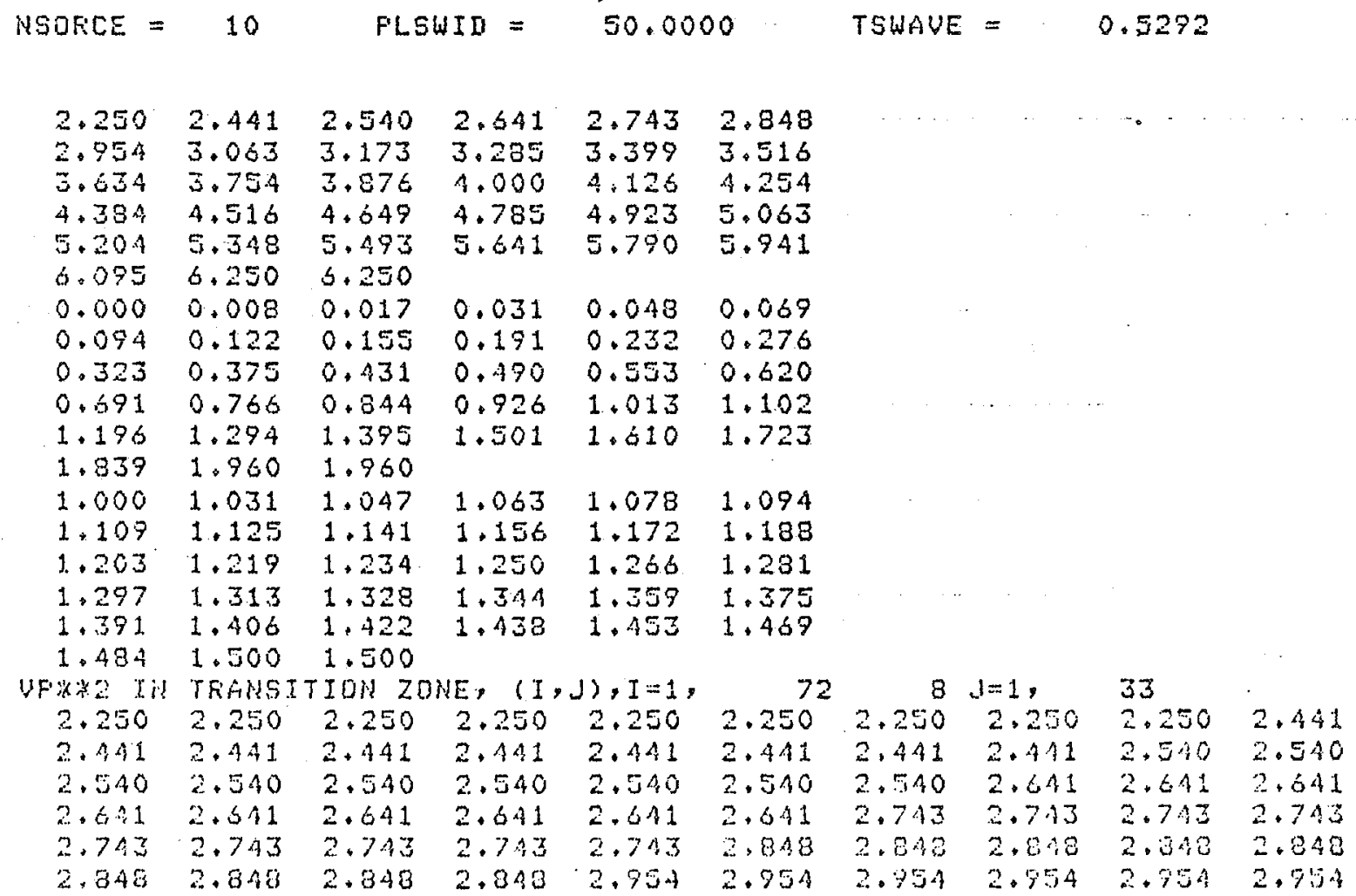


The following pages contain contour plots of the snap-shot files. A few words of explanation about the format of these plots will help in understanding them. The FILEID and time step number are in the lower right corner of each plot. The number in the lower left corner is the scaling factor used for the plot, which is selected by the plot program. In some cases, we have used the same scaling for all timesteps, and in others, we have used a different scale for each timestep. The dashed lines indicate negative contours. 
Figure 3

Contour plots of snap-shot files from file STEVI
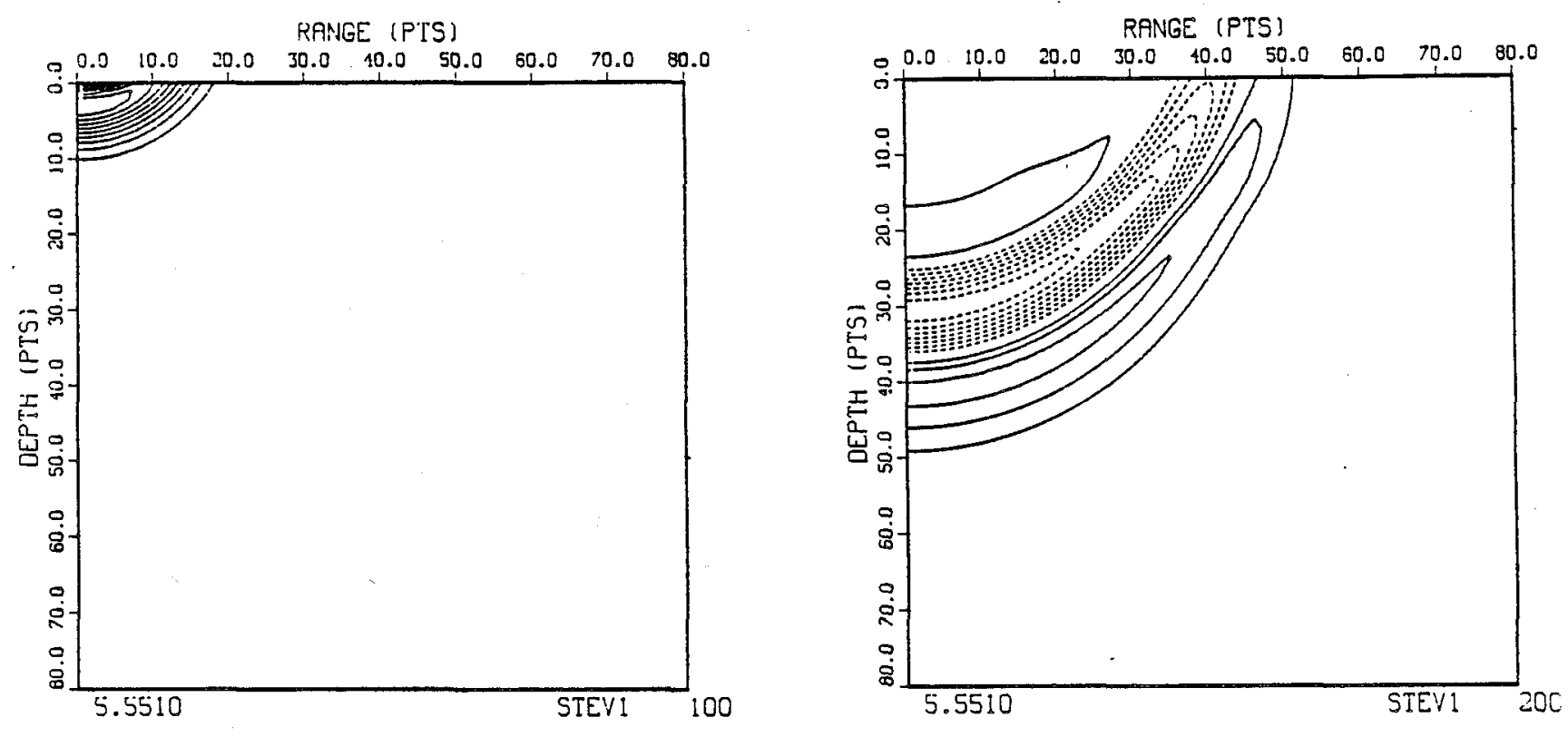

RANGE (PIS)

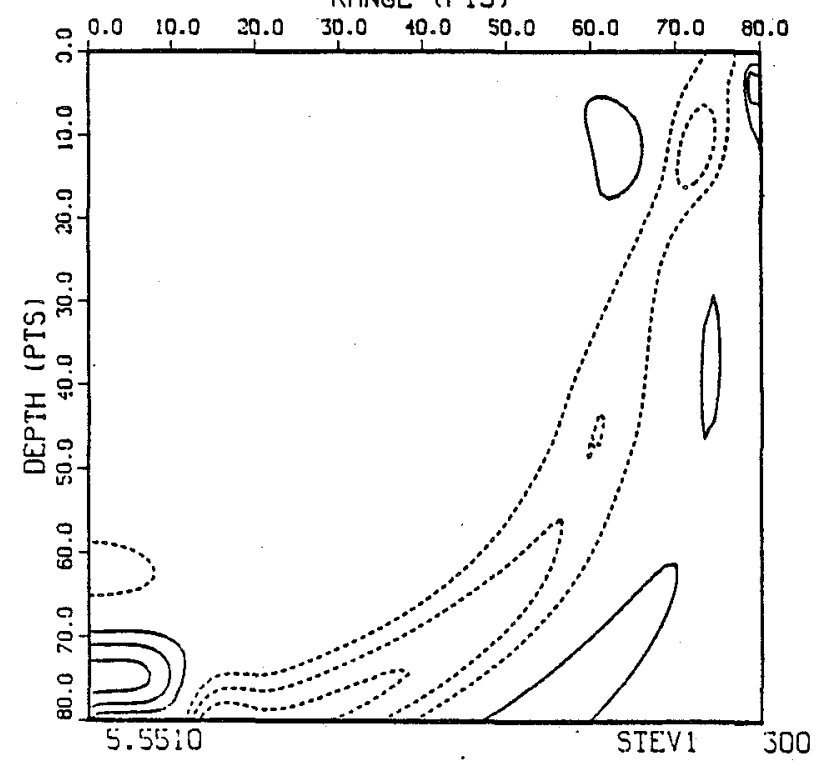


Figure 4

Contour plots of snap-shot files from model STEV2
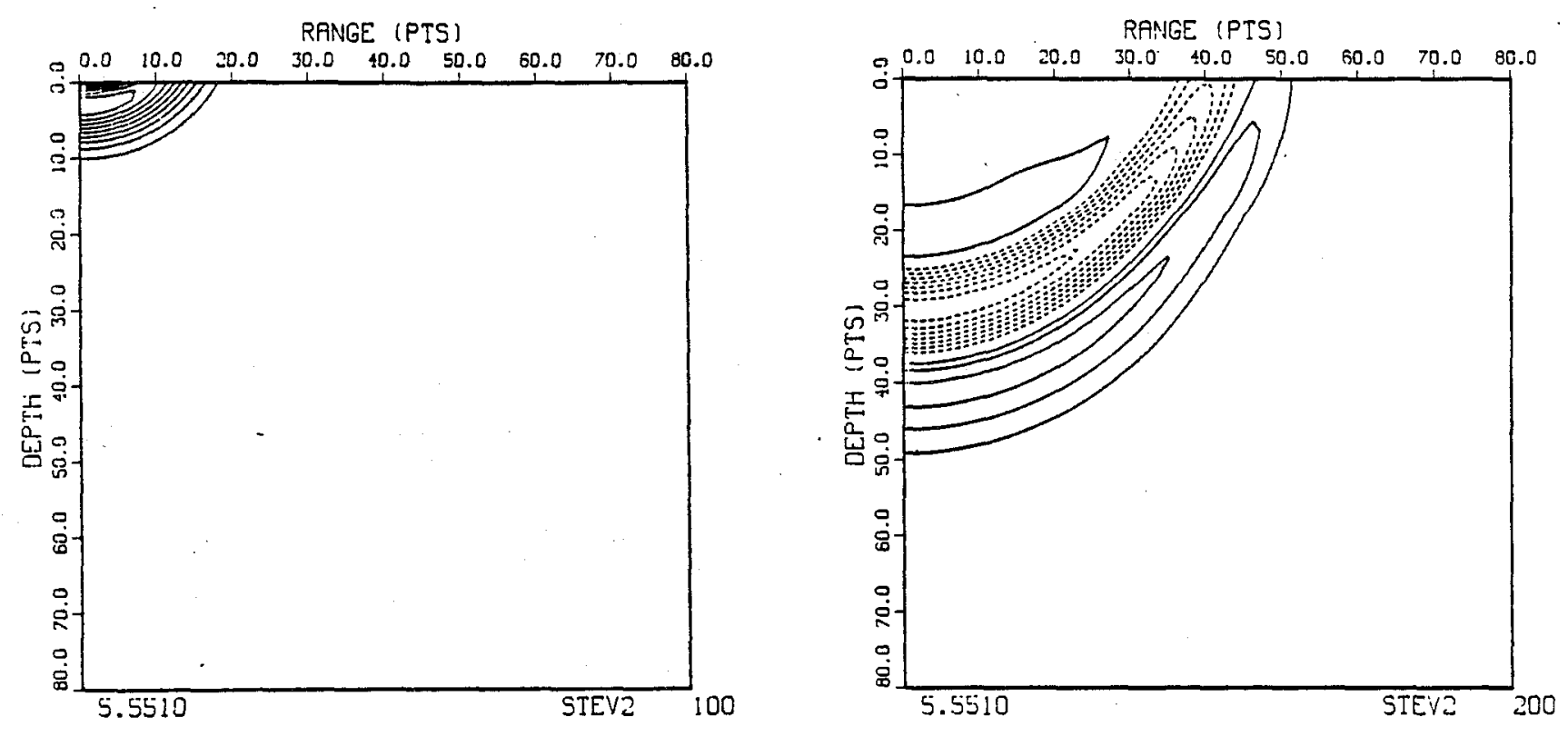

RANGE (PTS)

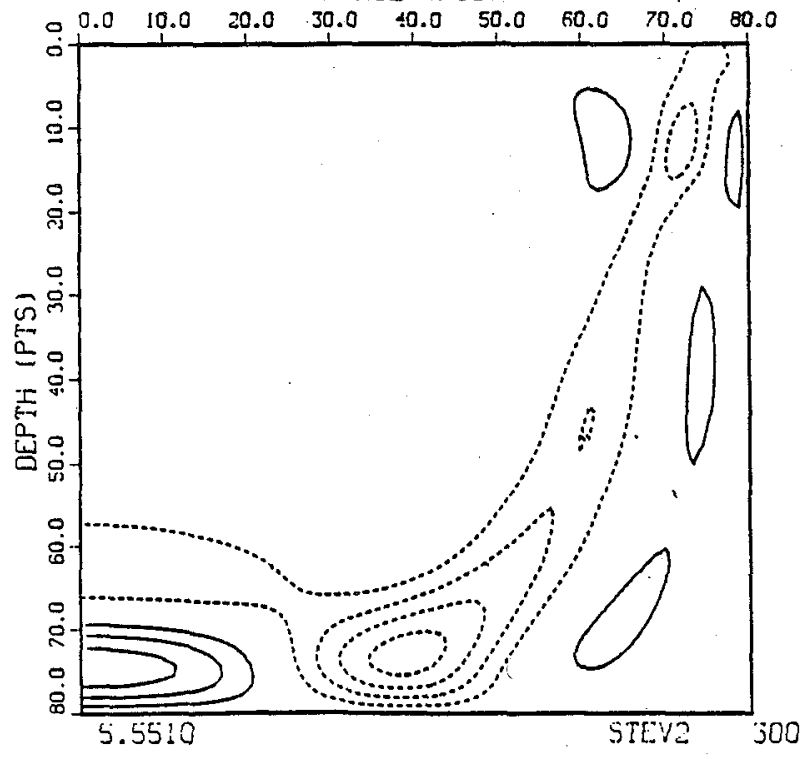


Figure 5

\section{Contour plots of snap-shot files from model STEV3}

RANGE (PTS)

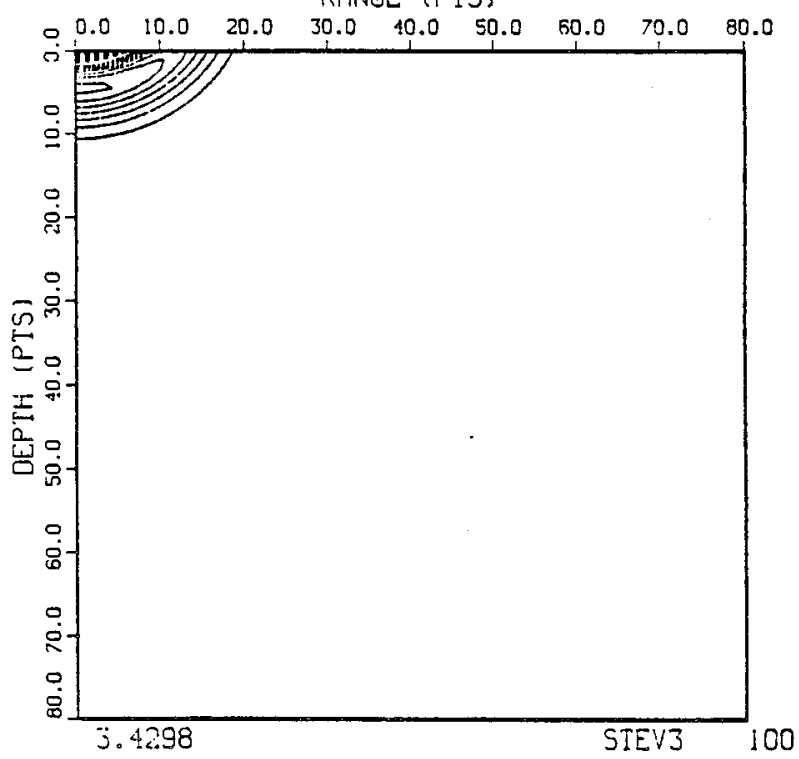

RPNGE (PTS)

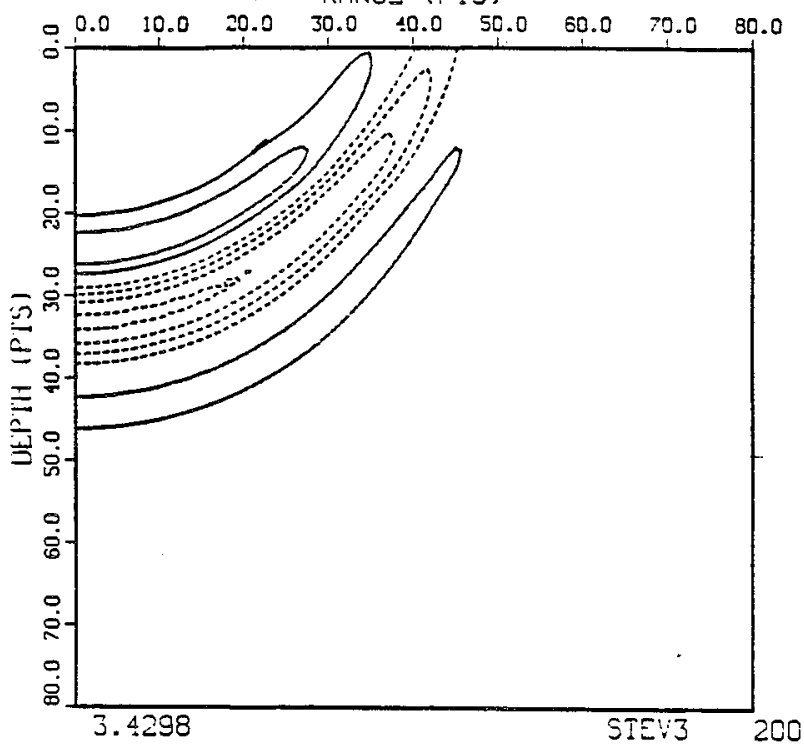

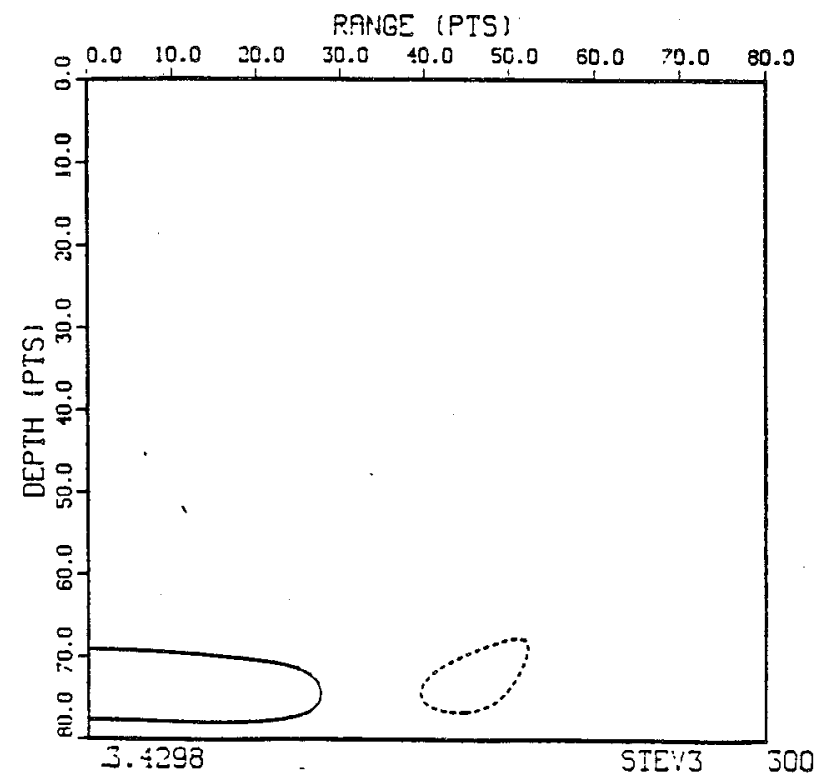


Figure 6

Contour plots of snap-shot files from model STEV4
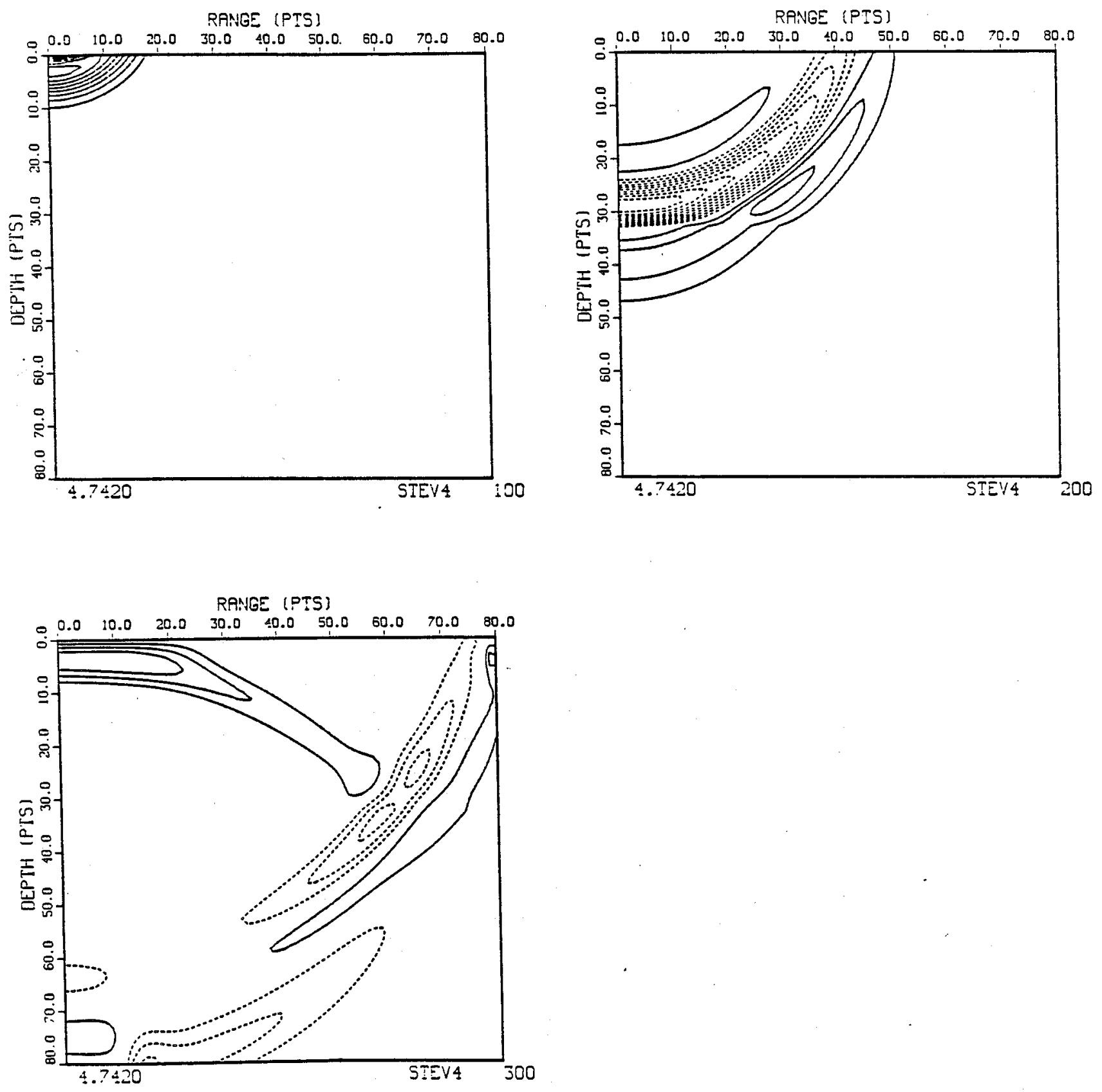
Figure 7

Contour plots of snap-shot files from model STEVS .
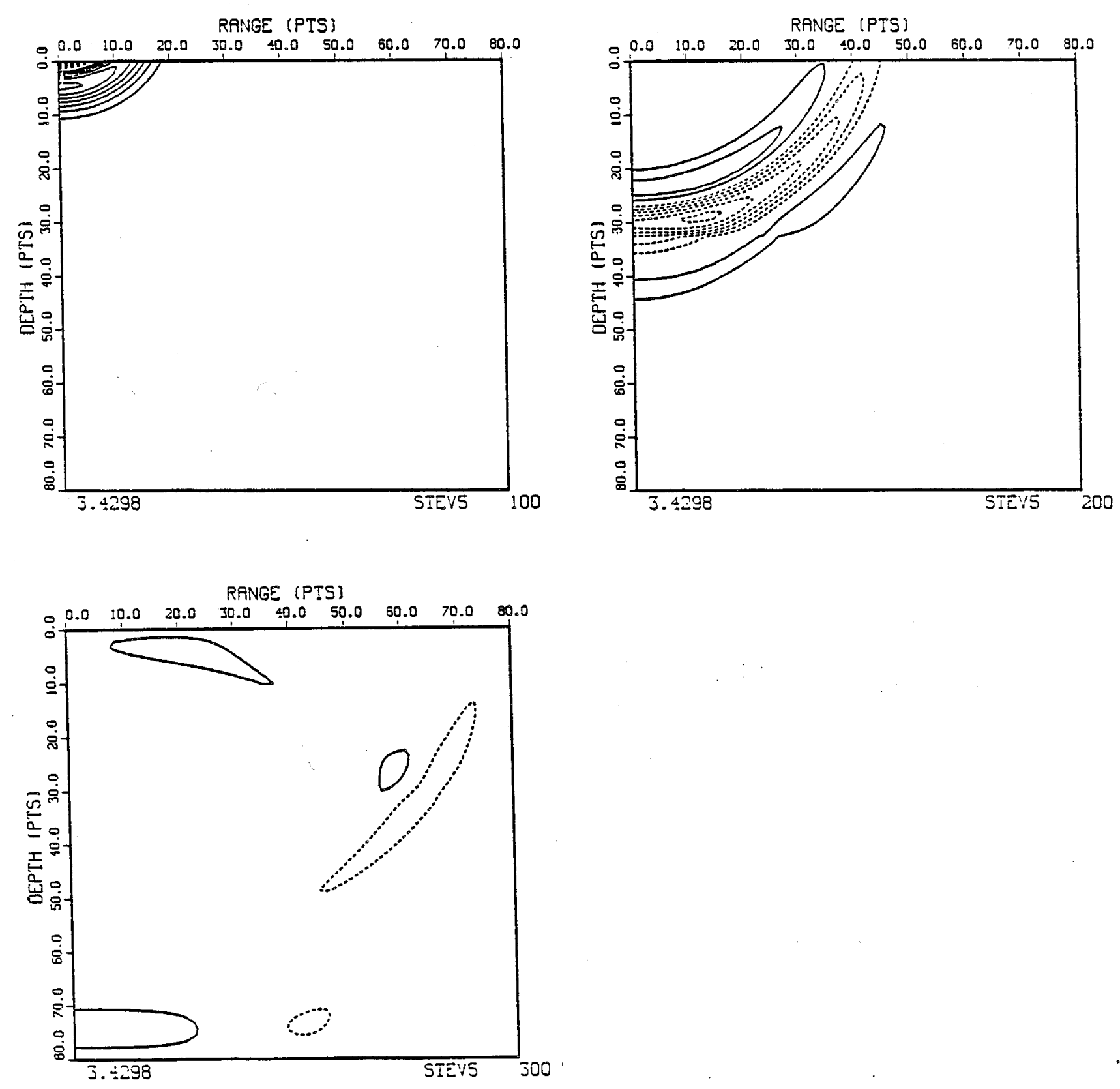
Figure 8

Contour plots of snap-shot files from model STEVA.
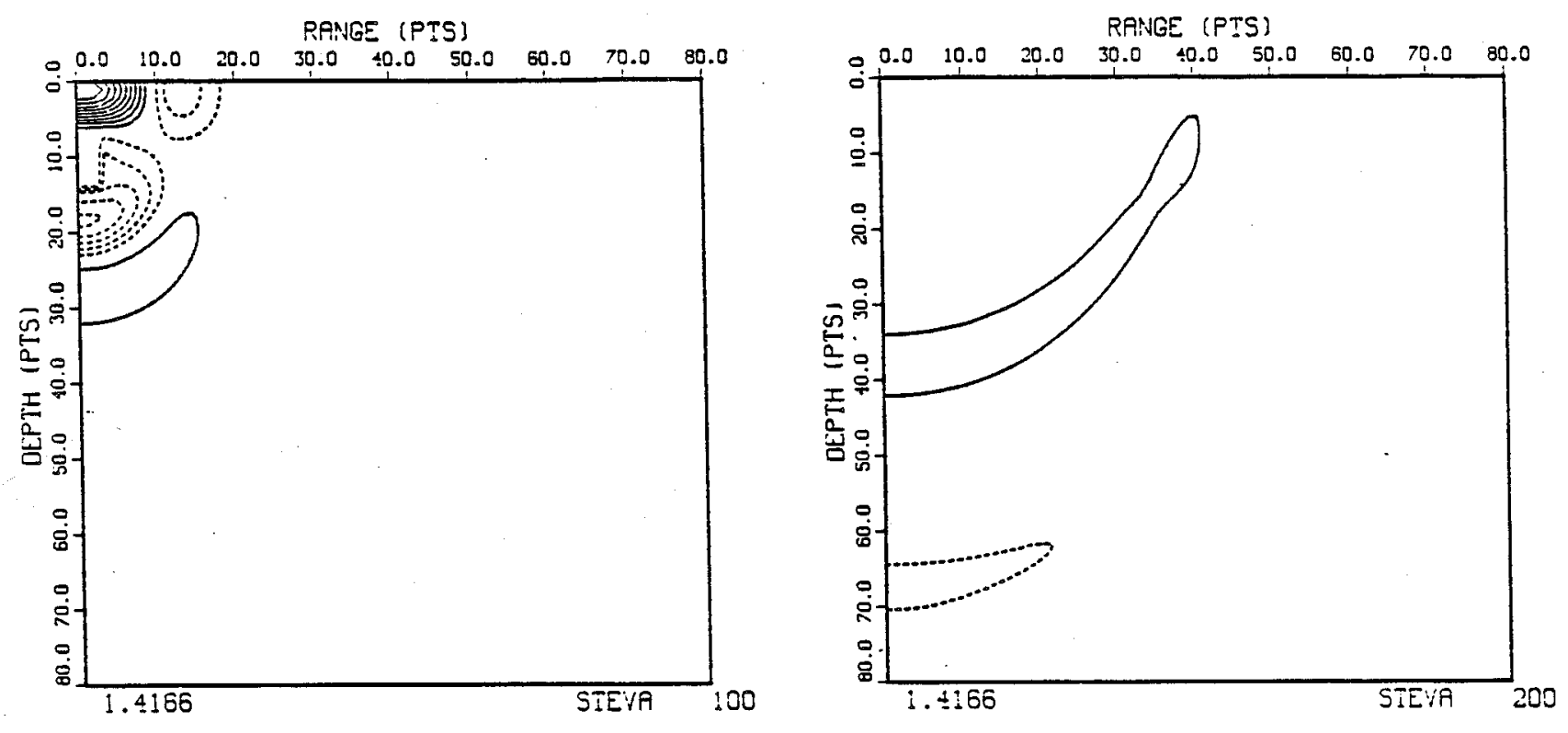

RAASEE (PTS)

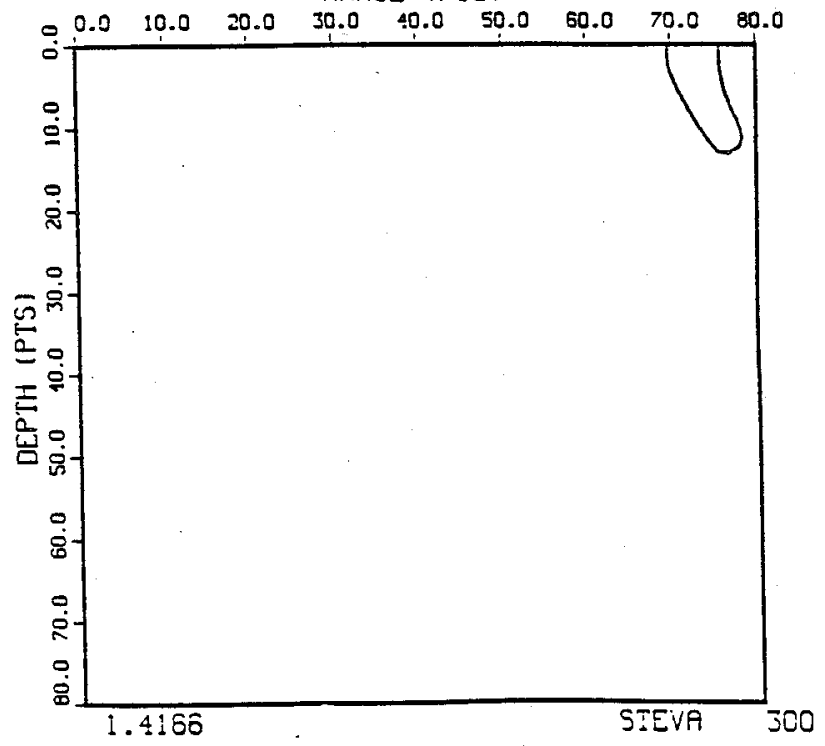


Figure 9

Contour plots of snap-shot files from model STEVB
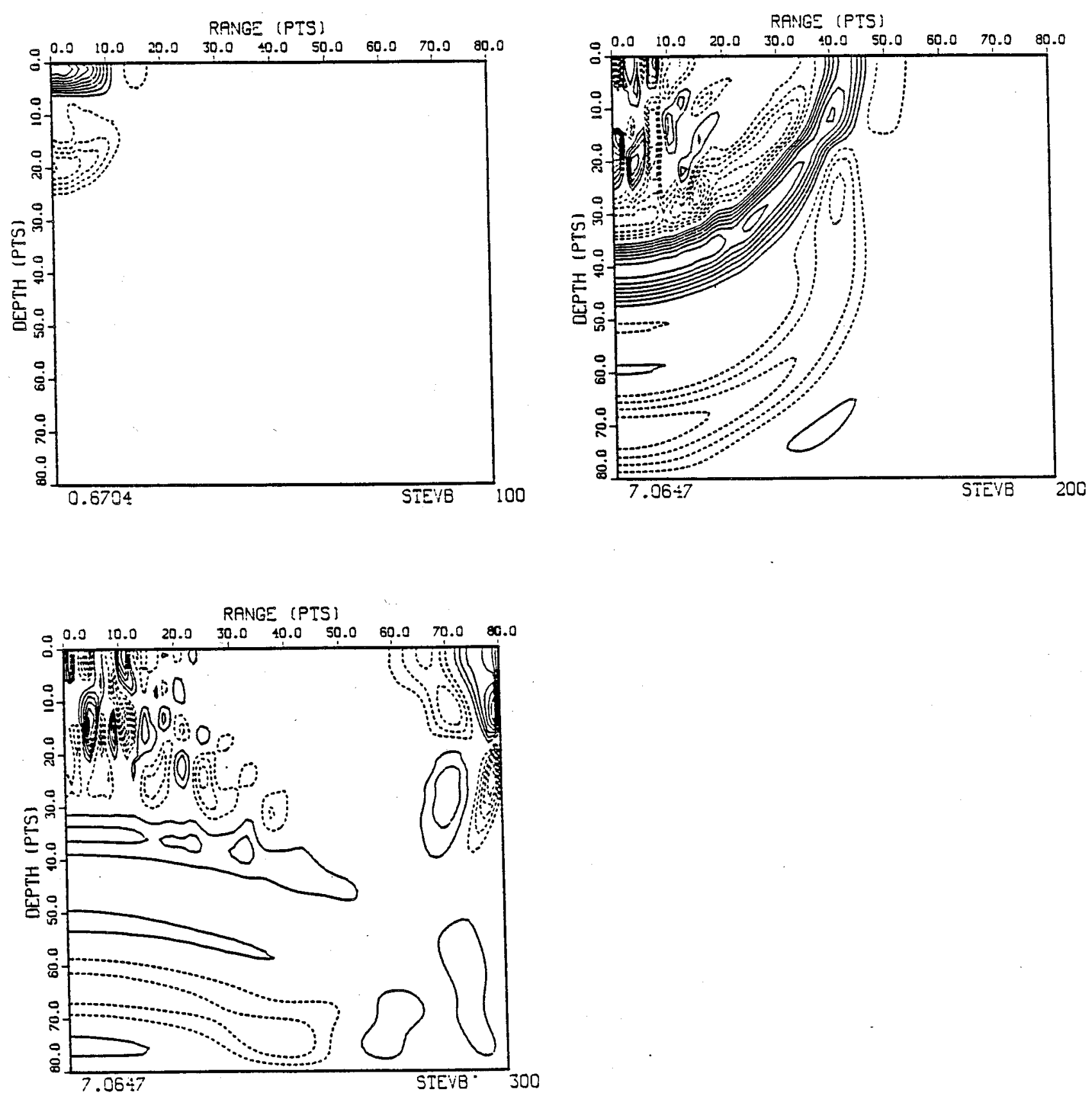
Figure 10

Contour plots of snap-shot files from model STEVC
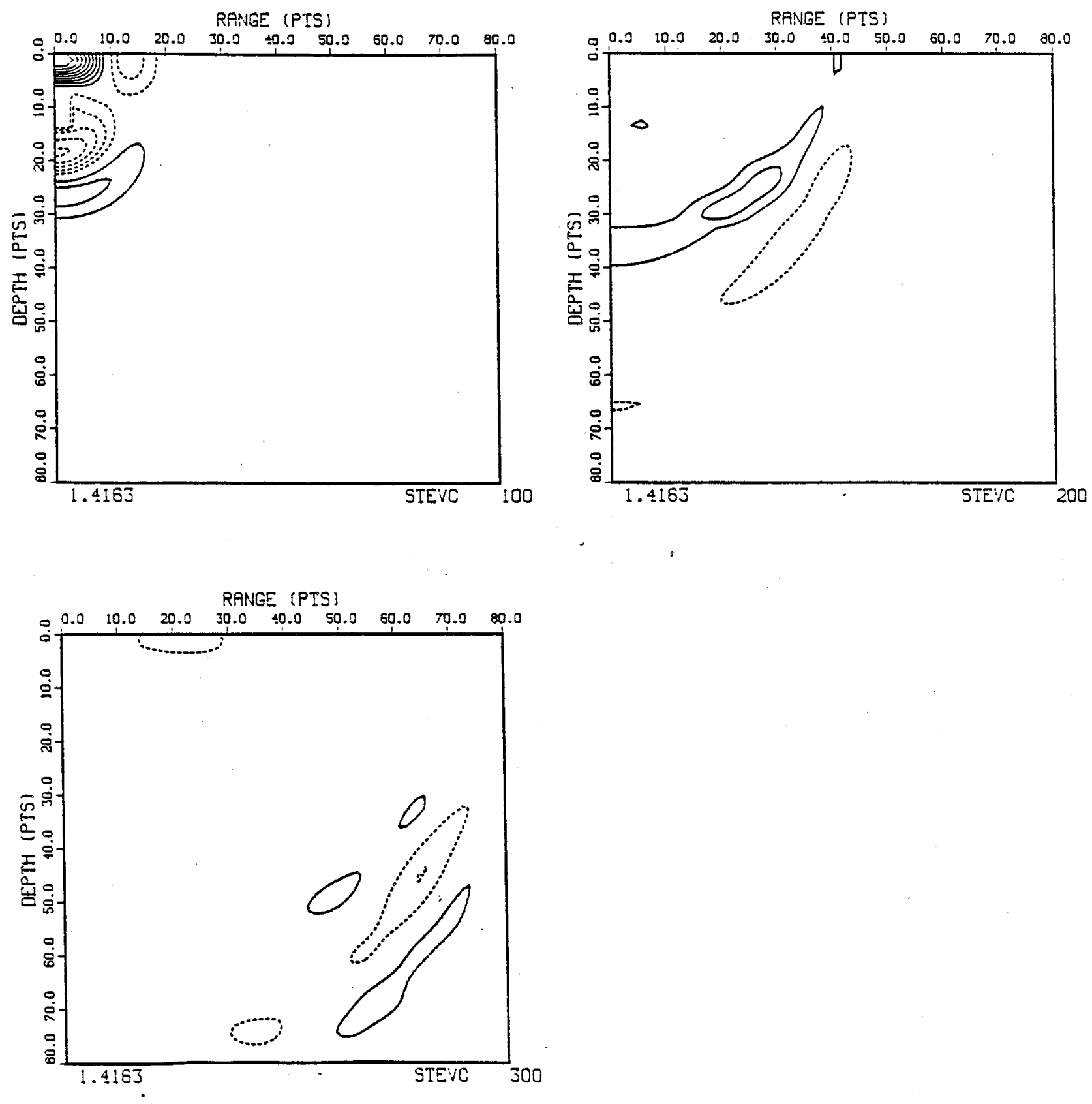
Figure 11

Contour plots of snap-shot files from model STEVD
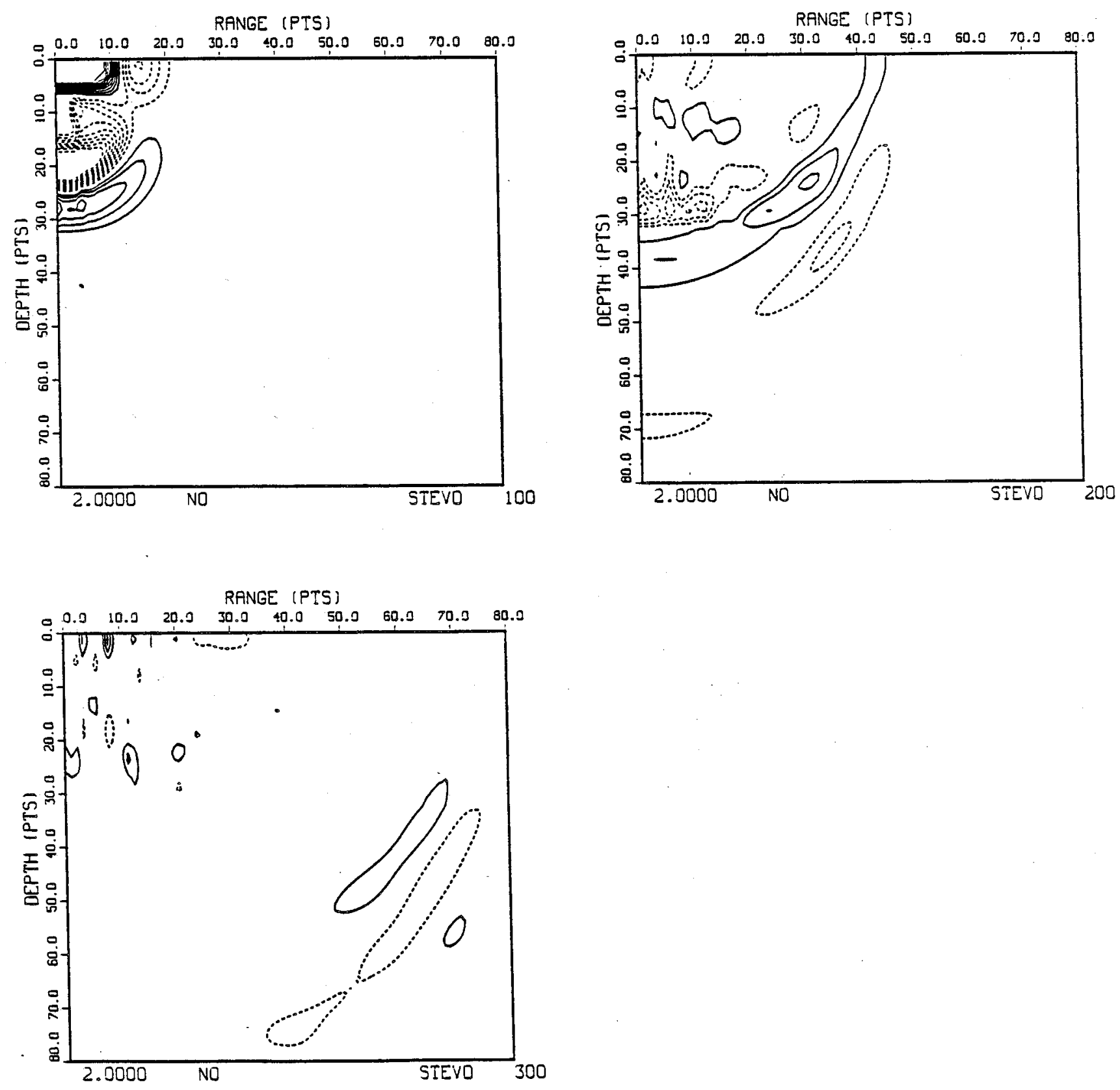
Figure 12

Plots of time series files of STEV1, STEV2, STEV3, and STEV4

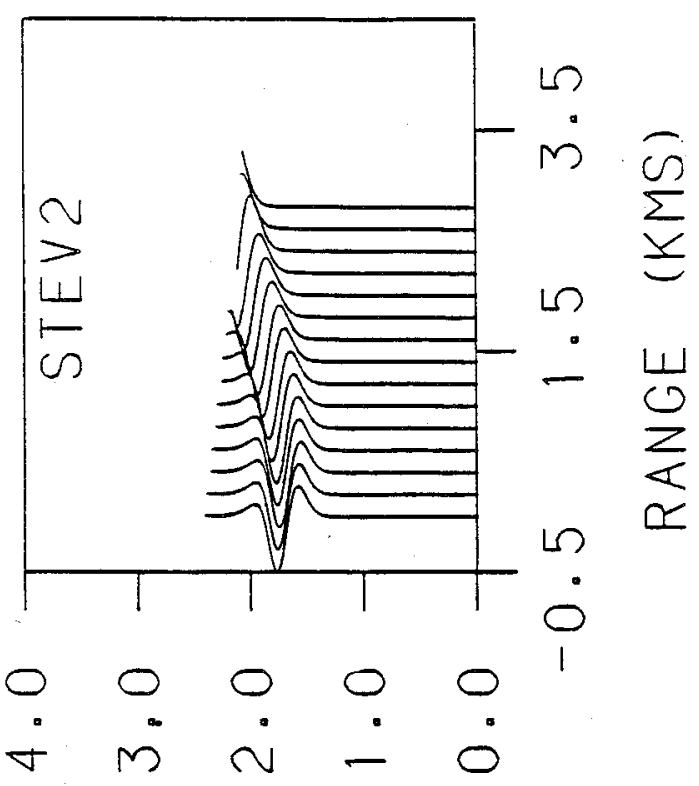

(SつヨS) $\exists W I L$
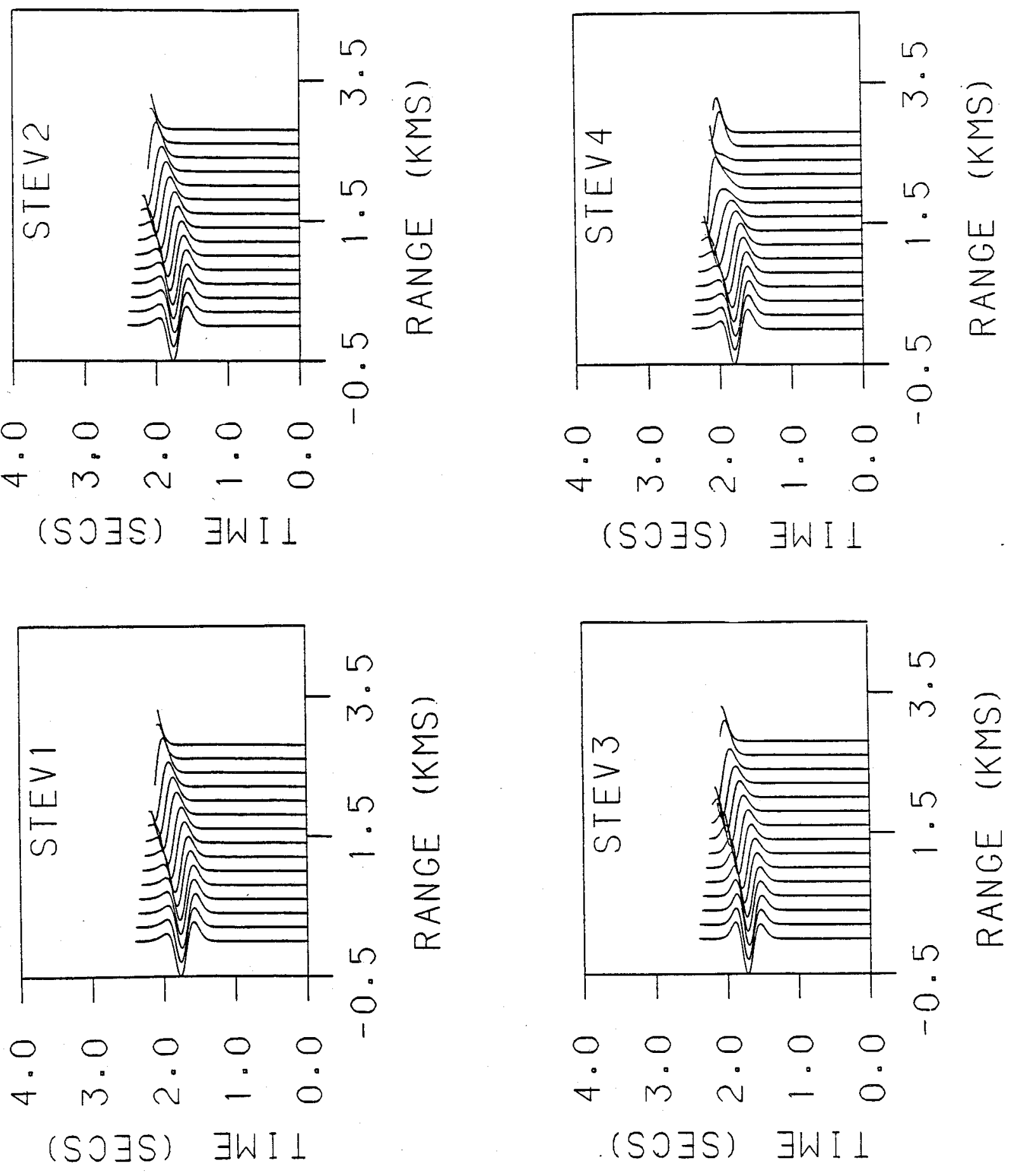


\section{Notes on Parameter Specifications}

The values used in the parameter file cannot be chosen arbitrarily. For stability of the code

$$
\Delta t \leq \frac{\min (\Delta r, \Delta z)}{\left.\sqrt{\alpha^{2}+\beta^{2}}\right]_{\max } .} \quad, \quad \alpha=\sqrt{\frac{\lambda+2 \mu}{\rho}} \quad, \quad B=\sqrt{\frac{\mu}{\rho}}
$$

where $\alpha$ and $\beta$ are compressional and shear wave speeds. For acceptable grid dispersion one should choose at least ten grid points per wavelength at the upper half power frequency. That is

$$
\Delta x \leq \frac{\lambda_{1 / 2}}{10}=\frac{1}{10} \frac{a_{\min }}{f_{+1 / 2}}
$$

For the Kelly source (the Alterman source is not recommended) the center frequency for displacement is $f_{0}=0.318 \sqrt{\xi}$ and the upper half power frequency is $f+1 / 2=0.458 \sqrt{\xi}$.

Codes without density variations have not yet been written so IDENS is always one. Also the absorbing boundaries only work for rectangular co-ordinates. This program contains only explicit codes so IEXPL is always one. When IFLAT equals one the source is introduced along the top of the grid as if the source were above the box (ND is negative) and NSW and MSW are not used.

When IFLAT equals zero the source is introduced on the edges of an MSW $X$ NSW box at the axis of symmetry centered at depth ND (positive). TSWAVE should be chosen so that the initial disturbance at the grid is small $\left(\sim 10^{-6}\right)$. Examples of a number of different options are included in the test runs. 
XI. References

1. Alterman, Z. S. and Karal, F. C. Jr. 1968 BSSA, 58, 367-398.

2. Alterman, Z. S. and Loewentha T, D. 1972 Methods in Computational Physics v.12 Alder, B. et al, Editors

3. Ilan, A., Ungar, A. and A1 terman, Z. 1975 GJAS, 43, 727-745.

4. Kelly et al. 1976 Geophysics, $\underline{41} 2-27$

5. Il an, A. and Loewentha1, D. 1976 Geophys. Prosp., 24 431, 453

6. Stephen, R. A. 1983 Geophys. J. R. astr. Soc., 72, 39-58.

7. Emerman, S. N. and Stephen, R. A. 1983. Bul1. seis. Soc. Am., 73, $661-665$. 


\section{APPENDIX}

Performance Evaluation

The calculation of synthetic seismograms by finite difference methods requires significant amounts of CPU time and computer memory. Throughout the program development we have tried to minimize the resources required, to enable us to run larger and more complex models at reasonable cost. During March, 1981 a study was conducted to determine how the relation between working set size and program size affects CPU time and page faults. Three different sized models (1.2 Mbyte, 1.8 Mbyte, and 2.7 Mbyte) were run with working set sizes varying from 400 to 4000 pages. Table $V$ summarizes the results.

It will be noted that, for each size model, there is a critical working-set size, where the number of page faults is drastically reduced. Nothing is gained by increasing the working-set size above this critical size. It will also be noted that the difference between the program size and the critical working-set size is the same for each model. This constant, we can assume, is the size of the code which is only executed once, while the critical working-set size includes the arrays used in the computation and the repeated code. Since the largest model in these tests is still a small model, and the 4000 page working-set required was pushing the limit of the VAX, it is obvious that some drastic steps would be required to run even moderately large models economicaliy on the VAX.

A second group of tests was made to determine the effect of using 1 arger arrays than needed for the model. A model which would have required 1.5 Mbytes was run in a program of 1.8 Mbytes and one of 2.7 Mbytes. The results are given in Table VI. Although the working sets used were below the critical size in each case, it can be seen that CPU time was reduced substantially by using the smaller arrays. This is the reason for recompiling and relinking the programs for each model. 
Table $V$

Relation between program size, working-set size, and page faults.

\begin{tabular}{l} 
PAGE \\
FAULTS \\
\hline
\end{tabular}

2997

2258

2229

1271

1289

1240

1238

1227

1353
CPU TIME

6.92

6.54

6.55

6.08

6.03

6.07

6.17

7.13

6.99
PEAK

WORK ING

SET SIZE

400

600

800

1000

1129

1130

1131

1141

1141
DEFAULT

WORK ING

SET SIZE

400

600

800

1000

1200

1400

1600

1800

2000

\subsection{Mbyte model (2392 pages)}

PAGE

FAULTS

33705

28458

25887

25790

2443

2442

2442

2442
PAGE

FAULTS

41637

41121

36857

30381

30695

34092

41383

4189
PEAK
WORKING

SET SIZE

75.81

74.53

72.97

73.06

63.24

63.63

63.63

64.71
500

1000

1500

2000

2318

2322

2326

2331
DEFAULT WORK ING

SET SIZE

500

1000

1500

2000

2500

3000

3500

4000

1.8 Mbyte mode1 (3595 pages) 
Table VI

PAGE

FAULTS

35537

30114

31200

29764

28103

25655

23946

22867

21394

23176
CPU TIME

83.91

84.36

81.57

82.33

84.62

85.16

84.76

83.98

82.61

83.68
PEAK

WORKING

SET SIZE

200

400

600

800

1000

1200

1400

1600

1800

2000
DEFAULT

WORK ING

SET SIZE

200

400

600

800

1000

1200

1400

1600

1800

2000

1.5 Mbyte model in 2.7 Mbyte program (5267 pages)

PAGE

FAULTS

35660

34002

33617

31749

26455

25930

25590

25913

25666

25767
PEAK

WORKING

CPU TIME

78.57

7.8 .41

77.99

76.35

74.89

75.20

73.97

74.66

74.19

73.84
SET SIZE

200

400

600

800

1000

1200

1400

1600

1800

2000
DEFAULT

WORK ING

SET SIZE

200

400

600

800

1000

1200

1400

1600

1800

2000

1.5 Mbyte model in 1.8 Mbyte program (3595 pages) 
As a result of these studies it became clear that more computing power would be necessary to run "real-world" models. The first step was to increase the physical memory of the VAX from 2.5 to 4.0 megabytes. The performance when running small to moderate models was improved, but it was still not reasonable to run large models.

Array Processors were then explored as a means of improving performance. The Floating Point Systems family of array processors was chosen as a possibility and a series of bench-marks was run. Table VII summarizes the results. It is obvious that the VAX/AP performance is degraded by the excessive amount of I/O between the VAX and the AP. In fact, even moderate-sized models are I/0 bound. Until the I/O bandwidth is increased, or sufficient AP memory is available, the array processor is not the solution.

The only remaining option seemed to be the use of a super computer. In December 1982, a contract was signed with Control Data Corporation to establish a CYBERNET SERVICES link to a CYBER-205. The initial code conversion was performed by Stu Gould of C.D.C.; he also provided vectorized code for two main loops in the TSTEP routine. Work began in February 1983 in Woods Hole via a 300 BAUD dial-up phone line. After operational details had been ironed out, successful runs of both the scalar and vector codes were made. A comparison of CYBER-205 and VAX timing and cost is shown in Table VIII.

It must be realized that while these figures provide a "ball-park" idea of efficiency, they are not exactly comparable. VAX charges reflect only CPU cost while CYBER charges are total costs. This error is about 10 . The vector code becomes more efficient as the model size increases, leading us to expect more favorable costs for a larger mode1. Finaliy, the CYBER-205 runs were done during prime shift, which adversely affects wall-clock time, while the VAX run was non-prime shift on a dedicated machine, optimizing wal1-clock time.

Since that time, work has been progressing toward implementing a later version of the programs in the CYBER-205. Preliminary tests indicate that the unvectorized code runs about 60 times faster on the CYBER for 1 arge models. We hope for even further savings by completing the vectorization of the TSTEP routines. 
Table VII

PERFORMANCE SUMMARY

\begin{tabular}{lrlrlll|rrr} 
& \multicolumn{2}{c}{ VAX/AP } & \multicolumn{2}{c}{ VAX } & \multicolumn{2}{c}{ PERFORMANCE } & \multicolumn{2}{c}{ DIRECT } \\
PARAMETER & \multicolumn{2}{c}{ WALL } & CPU & WALL & CPU & \multicolumn{2}{c}{ IMPROVEMENT } & \multicolumn{2}{c}{ I/0 COUNT } \\
FILE & TIME2 & TIME & TIME & TIME & WALL & CPU & VAX/AP & VAX \\
BM005 & 57 & 2.20 & 98 & 96.13 & 1.72 & 43.70 & 162 & 10 \\
BM006 & 92 & 19.14 & 99 & 97.38 & 1.08 & 5.09 & 1862 & 36 \\
BM008 & 312 & 136.12 & 121 & 117.64 & 0.39 & 0.86 & 11546 & 27
\end{tabular}

NOTE: 1. FDAP was executed with parameter file BM005 and BM006. FDAPSEG was executed with parameter file BMO08.

2. A11 times are in seconds.

3. This is defined as VAX time divided by VAX/AP time.

CONFIGURATION STATISTICS

VAX $11 / 780$

VMS V2.01

Default Working Set $=150$

1.25 MBYTE Memory

No Other Users
$\underline{A P-120 B}$

APFORTRAN V2.02

64K Words 167ns. Main Data Memory

4K Words Program Source Memory 
Table VIII

\begin{tabular}{|c|c|c|c|c|}
\hline & $\begin{array}{c}\text { CPU } \\
\text { SECONDS }\end{array}$ & $\begin{array}{l}\text { WALL CLOCK } \\
\text { SECONDS }\end{array}$ & $\begin{array}{l}\text { PRIME } \\
\text { SHIFT } \\
\text { COST } \\
\end{array}$ & $\begin{array}{c}\text { NON-PRIME } \\
\text { SHIFT } \\
\text { COST } \\
\end{array}$ \\
\hline $\begin{aligned} & \operatorname{VAX} 11 / 780 \\
&(2 \text { megabytes })\end{aligned}$ & 857.3 & 995.7 & $\$ 28.30$ & $\$ 14.15$ \\
\hline $\begin{array}{r}\text { CYBER-205 } \\
(\text { Scalar) }\end{array}$ & 23.2 & 88.0 & $\$ 27.81$ & $\$ 14.42$ \\
\hline $\begin{array}{r}\text { CYBER-205 } \\
\text { (vector) }\end{array}$ & 17.6 & 27.0 & $\$ 21.87$ & $\$ 11.34$ \\
\hline
\end{tabular}




\begin{tabular}{|c|c|c|}
\hline $\begin{array}{l}\text { REPORT DOCUMENTATION } \\
\text { PAGE }\end{array}$ & $\begin{array}{l}\text { 1. REPORT NO. } \\
\text { WHOI-83-42 }\end{array}$ & 3. Recipient's Accession No. \\
\hline \multirow{2}{*}{\multicolumn{2}{|c|}{$\begin{array}{l}\text { 4. Title and Subtitle } \\
\text { FINDIF: A Software Package to Create Synthetic Seismograms by } \\
\text { Finite Differences }\end{array}$}} & $\begin{array}{l}\text { 5. Report Date } \\
\text { November } 1983\end{array}$ \\
\hline & & 6. \\
\hline \multicolumn{2}{|c|}{$\begin{array}{l}\text { 7. Author(s) } \\
\text { Mary M. Hunt, Lee Gove, and Ralph A. Stephen }\end{array}$} & $\begin{array}{l}\text { 8. Performing Organization Rept. No. } \\
\text { WHOI }-83-42\end{array}$ \\
\hline \multirow{2}{*}{\multicolumn{2}{|c|}{$\begin{array}{l}\text { 9. Performing Organization Name and Address } \\
\text { Woods Hole Oceanographic Institution } \\
\text { Woods Hole, Massachusetts } 02543\end{array}$}} & $\begin{array}{l}\text { 10. Project/Task/Work Unit No. } \\
\text { NR } 083-004\end{array}$ \\
\hline & & $\begin{array}{l}\text { 11. Contract(C) or Grant(G) No. } \\
\text { (C) } \mathrm{N} 00014-79-\mathrm{C}-0071 \text {; } \\
\text { (G) }\end{array}$ \\
\hline \multirow{2}{*}{\multicolumn{2}{|c|}{$\begin{array}{l}\text { 12. Sponsoring Organization Name and Address } \\
\text { Office of Naval Research } \\
\text { Environmental Sciences Directorate } \\
\text { Arlington, Virginia } 22217\end{array}$}} & $\begin{array}{l}\text { 13. Type of Report \& Period Covered } \\
\text { Technical }\end{array}$ \\
\hline & & 14. \\
\hline
\end{tabular}

15. Supplementary Notes

This report should be cited as: Woods Hole Oceanog. Inst. Tech. Rept. WHOI-83-42.

16. Abstract (Limit: 200 words)

In order to study seismic wave propagation through laterally varying sea floor structures, a software package has been created to generate synthetic seismograms by finite differences. The elastic wave equation can be solved in two dimensions either for point sources in cylindrical coordinates or for line sources in rectangular coordinates. Vertical and radial variations of the elastic parameters are allowed.

The package includes four programs. Input to the system consists of a short file containing parameter values to describe the model. The first program is used to initialize the system for the particular model being used. The source arrays and velocity matrices are each computed by a separate program. The final program, which actually carries out the finite difference calculations, includes six subroutines to implement different options based on alternative finite difference formulations. Two different kinds of output files are created by this program: one or more snapshot files, and one time series file, which will usually include more than one series.

17. Document Analysis a. Descriptors

1. Synthetic seismograms

2. Elastic wave equation

3. Finite differences

b. Identifiers/Open-Ended Terms

c. COSATI Field/Group

18. Availability Statemen:

Distribution Unlimited

\begin{tabular}{|l|l|}
\hline $\begin{array}{c}\text { 19. Security Class (This Report) } \\
\text { Unclassified }\end{array}$ & $\begin{array}{c}\text { 21. No. of Pages } \\
45\end{array}$ \\
\hline 20. Security Class (This Page) & 22. Price \\
\hline
\end{tabular}




\title{
DOCUMENT LIBRARY
}

\author{
February 1, 1984 \\ DISTRIBUTION LIST \\ BIBLIOGRAPHY AND TECHNICAL REPORT EXCHANGE
}

Library

R.S.M.A.S.

University of Miami

4600 Rickenbacker Causeway

Miami, FL 33149

Fisheries-Oceanography Library

151 Oceanography Teaching Bldg.

University of Washington

Seattle, WA 98195

Institute of Marine Sciences Library

University of Alaska

O'Neill Building

905 Koyukuk Ave. North

Fairbanks, AK 99701

Pell Marine Science Library

University of Rhode Island

Narrangansett Bay Campus

Narrangansett, R.I. 02882

Institute of Geophysics

University of Hawaii

Library Room 252

2525 Correa Rd.

Honolulu, HI 96822

NOAA/EDIS Miami Library Center

4301 Rickenbacker Causeway

Miami, FL 33149

Library

Chesapeake Bay Institute

4800 Atwell Rd.

Shady Side, MD 20867

Working Collection

Texas A \& M University

Dept. of Oceanography

College Station, TX 77843
Hancock Library of Biology \& Oceanography

Alan Hancock Laboratory

University of Southern California

Los Angeles, CA 90007

Library

Lamont-Doherty Geological Observatory

Columbia University

Palisades, NY 10964

Library

Physical Oceanographic Laboratory

Nova University

8000 N. Ocean Drive

Dania, FL 33304

Library

Skidaway Institute of Oceanography

P. O. Box 13687

Savannah, GA 31406

U.S. Coast Guard Oceanographic Unit Library

Bldg. 159 E. Navy Yard Annex

Washington, DC 20590

Library

Virginia Institute of Marine Science

Gloucester Point, VA 23062

MIT Libraries

Serial Journal Room 14E-210

Cambridge, MA 02139

Director, Ralph M. Parsons Laboratory

Room 48-311

MIT

Cambridge, MA 02139

Marine Resources Information Center

Bldg E38-320

MIT

Cambridge, MA 02139

Attn: Stella Sanchez-Wade

Documents Section

Scripps Institute of Oceanography

Library, Mail Code C-075C

La Jolla, CA 92093 
FOR UNCLASSIFIED TECHNICAL REPORTS, REPRINTS, AND FINAL REPORTS PUBLISHED BY OCEANOGRAPHIC CONTRACTORS OF THE OCEAN SCIENCE AND TECHNOLOGY DIVISION OF THE OFFICE OF NAVAL RESEARCH

(Revised October 1983)

1 Deputy Under Secretary of Defense

(Research and Advanced Technology)

Military Assistant for Environmental Science

Room 3D129

Washington, DC 20301

Office of Naval Research

800 North Quincy Street

Arlington, VA 22217

3 Attn: (Code applicable to Program) *

1 Attn: Code $420 \mathrm{C}$

2 Attn: Code $102 \mathrm{C}$

Commanding Officer

Naval Research Laboratory

Washington, DC 20375

6 Attn: Library Code 2627

1 Attn: Library Code 2620, Mr. Peter Imhof

12 Defense Technical Information Center

Cameron Station

Alexandria, VA 22314

Attn: $D C A$

Commander

Naval Oceanographic Office

NSTL Station

Bay St. Louis, MS 39522

1 Attn: Code 8100

1 Attn: Code 6000

1 Attn: Code 3300

1 NODC/NOAA

Code D781

Wisconsin Avenue, N.W.

Washington, DC 20235

* Applicable Codes: 422 (PO); 422CB (Chem/Bio); 422CS (Coastal); 425 (G\&G); 425AR (Arctic); 421 (OE); 421SP. (Ships); 425OA (Ocean Acoustics); 425UA (Underwater Acoustics) 